Cahiers $d u$ MONDE RUSSE

\section{Cahiers du monde russe}

Russie - Empire russe - Union soviétique et États indépendants

$46 / 3 \mid 2005$

Etrangers en Russie, Russes à l'étranger

\title{
Les écoles étrangères dans la sociéte russe à l'époque des Lumières
}

\section{Vladislav Rjéoutski}

\section{(Q) OpenEdition \\ Journals}

Édition électronique

URL : https://journals.openedition.org/monderusse/8819

DOI : 10.4000/monderusse.8819

ISSN : $1777-5388$

Éditeur

Éditions de l'EHESS

\section{Édition imprimée}

Date de publication : 1 juillet 2005

Pagination : 473-527

ISBN : 2-7132-2056-4

ISSN : $1252-6576$

Référence électronique

Vladislav Rjéoutski, «Les écoles étrangères dans la sociéte russe à l'époque des Lumières 》, Cahiers du monde russe [En ligne], 46/3 | 2005, mis en ligne le 01 janvier 2007, consulté le 03 septembre 2022. URL : http://journals.openedition.org/monderusse/8819; DOI : https://doi.org/10.4000/monderusse. 8819 
chercher : repérer : avancer

Cet article est disponible en ligne à l'adresse :

http://www.cairn.info/article.php?ID REVUE=CMR\&ID NUMPUBLIE=CMR 463\&ID ARTICLE=CMR 4630473

\title{
Les écoles étrangères dans la sociéte russe à l'époque des Lumières
}

\author{
par VLADISLAV RJÉOUTSKI
}

\section{Editions de I'EHESS | Cahiers du monde russe}

\author{
$2005 / 3$ - Vol 46 \\ ISSN 1252-6576 | ISBN 2713220564 | pages 473 à 527
}

Pour citer cet article :

-RJÉOUTSKI V., Les écoles étrangères dans la sociéte russe à l'époque des Lumières, Cahiers du monde russe 2005/ 3, Vol 46, p. 473-527.

Distribution électronique Cairn pour les Editions de l'EHESS.

(C) Editions de l'EHESS. Tous droits réservés pour tous pays.

La reproduction ou représentation de cet article, notamment par photocopie, n'est autorisée que dans les limites des conditions générales d'utilisation du site ou, le cas échéant, des conditions générales de la licence souscrite par votre établissement. Toute autre reproduction ou représentation, en tout ou partie, sous quelque forme et de quelque manière que ce soit, est interdite sauf accord préalable et écrit de l'éditeur, en dehors des cas prévus par la législation en vigueur en France. Il est précisé que son stockage dans une base de données est également interdit. 


\section{LES ÉCOLES ÉTRANGÈRES DANS LA SOCIÉTE RUSSE À L'ÉPOQUE DES LUMIÈRES*}

Les écoles privées dans le système d'éducation en Russie au XVIII siècle ont déjà attiré l'attention des historiens par le passé, mais il semble que, jusqu'à présent, on n'ait pas considéré qu'elles jouaient un rôle important : les études générales sur l'éducation en Russie ne les mentionnent même pas ou leur réservent bien peu de place ${ }^{1}$. La littérature spécialisée fait état du statut juridique de l'enseignement privé, de la politique du gouvernement à l'égard des établissements d'enseignement privé, et procure des éléments statistiques ${ }^{2}$. Cependant, on sait peu de choses

Particularités orthographiques: l'orthographe de l'original est respectée dans les citations ; l'orthographe présumée est signalée par (?) ; l'astérisque désigne les noms dont l'orthographe latine nous est inconnue et qui sont transcrits du russe selon les règles de la transcription savante.

* Je suis très reconnaissant pour leurs suggestions et corrections à mes collègues : Wladimir Berelowitch et Dmitri Gouzévitch (Centre d'études des mondes russe, caucasien et centre-européen, EHESS), Vladimir Somov (Conservatoire de Saint-Pétersbourg). Je remercie également Galina Smagina (Académie des sciences de Russie), Wladimir Berelowitch et Julie Ollivier-Chakhnovskaïa, agrégée d'histoire, pour les documents et les informations qu'ils ont mis à ma disposition.

1. Par exemple, P. N. Miljukov, Očerki po istorii russkoj kul'tury: V 3 t. T. 2 , č.2 : Iskusstvo, škola, prosveščenie [Essais sur l'histoire de la culture russe : l'art, l'école, l'instruction], M., 1994 ; P. L. Alston, Education and the State in Tsarist Russia, Stanford : Stanford University Press, 1969. Le chapitre intitulé «Catherine and the Foundation of the Russian Educational System » du livre d'Isabel de Madariaga, Politics and Culture in Eighteenth-Century Russia (Londres, New York : Longman, 1998, p. 168-191), donne un excellent résumé de la politique russe dans le domaine de l'éducation sous Catherine II ; on y trouve une description de l'inspection des pensionnats ainsi que quelques données statistiques.

2. Par exemple: A. S. Voronov, Istoriko-statističeskoe obozrenie učebnyh zavedenij SanktPeterburgskogo okruga s 1715 po 1828 god vključitel'no [Étude historique et statistique des établissements d'enseignement de la circonscription scolaire de Saint-Pétersbourg de 1715 à 1828 inclus], SPb., 1849 ; E. Lihačeva, Materialy dlja istorii ženskogo obrazovanija v Rossii. Kniga 1-3 [Matériaux pour l'histoire de l'éducation des femmes en Russie], 3 vol., SPb., 18901895, vol. 1 : 1086-1796 ; S. V. Roždestvenskij, Istoričeskij obzor dejatel'nosti Ministerstva Narodnogo Prosveščenija : 1802-1902 [Aperçu historique des activités du ministère de l'Instruction publique: 1802-1902], SPb., 1902; M. I. Demkov, Istorija russkoj pedagogiki, č. 2 : 
sur les pensionnats à vocation éducative, leur clientèle et les personnes à leur tête 3 . L'absence d'informations fiables a souvent conduit à se contenter de conjectures sur ces questions. Par exemple, la réputation d'incompétence des enseignants étrangers en général en Russie repose essentiellement sur les témoignages glanés dans les Mémoires russes du XVIII ${ }^{\mathrm{e}}$ siècle ; on retrouve encore aujourd'hui cette idée reprise sans aucune critique, comme une vérité absolue ${ }^{4}$.

Le pensionnat français est étudié ici comme exemple d'école étrangère privée dans une ville russe du XVIII ${ }^{\mathrm{e}}$ siècle. Toutefois les écoles tenues par des Français ne se distinguaient pas beaucoup des écoles fondées par les Allemands, d'autant qu'on trouvait des enseignants français dans presque tous les établissements étrangers. On peut noter cependant quelques particularités propres aux écoles françaises.

En Europe au Moyen Âge, les écoles primaires et secondaires étaient tenues par l'Église. Avec le temps, des écoles laïques et privées commencent à leur faire concurrence. Leur apparition est liée à l'intérêt que portent à l'éducation la noblesse

Novaja russkaja pedagogika : XVIII v. [Histoire de la pédagogie russe, $2^{e}$ partie : La nouvelle pédagogie russe : XVIII ${ }^{e}$ s.], M., 1910 ; P. F. Kapterev, Istorija russkoj pedagogiki [Histoire de la pédagogie russe], SPb., 1915. Un bon aperçu des études de la réforme scolaire sous Catherine II est donné par L. M. Artamonova, «Vlast’, obščestvo i prosveščenie v Rossii : problemy realizacii i vosprijatija škol’nyh reform konca XVIII - pervoj poloviny XIX vekov » [Pouvoir, société et éducation en Russie : problèmes de la réalisation et de la perception des réformes scolaires, fin $\mathrm{XVIII}^{\mathrm{e}}$-première moitié du XIX ${ }^{\mathrm{e}} \mathrm{s}$.], Istorija, $\mathrm{n}^{\circ} 1$, 2002. La question des écoles étrangères est abordée dans : L. Pingaud, Les Français en Russie et les Russes en France. L'Ancien régime, l'émigration, les invasions, Paris : Perrin, 1886; E. Haumant, La culture française en Russie, 1700-1900, Paris : Hachette, 1910 ; W. Berelowitch et O. Medvedkova, Histoire de Saint-Pétersbourg, Paris : Fayard, 1996.

3. Les études sur l'enseignement privé en Russie au XVIII' siècle sont rares. Les pensions sont étudiées sur la base des annonces de journaux par P. Stolpjanskij, « Častnye školy i pansiony Peterburga vo vtoroj polovine XVIII v. » [Les écoles et pensionnats privés de Saint-Pétersbourg dans la seconde moitié du XVIII ${ }^{\mathrm{e}} \mathrm{s}$.], ŽMNP, mars 1912, t. 38, Otdel po narodnomu obrazovaniju, p. 1-23. Nous citerons également le travail de S. V. Sergeeva, Častnoe obrazovanie $v$ Rossii : poslednjaja četvert' XVIII - pervaja polovina XIX VV. [L'enseignement privé en Russie, dernier quart du XVIII'-première moitié du XIXe s.], Penza, 2000. Pour le XVIII ${ }^{\mathrm{e}}$ siècle, l'auteur se base sur des études générales de l'histoire de ce siècle. L'enseignement privé du début du XIX ${ }^{e}$ est étudié plus en détail. Sur ce sujet, voir le travail déjà cité de S. V. Sergeeva et sa thèse : S. V. Troščina (Sergeeva), Guvernerstvo v domašnem obrazovanii Rossii v pervoj polovine $X I X$ veka [Le système des gouverneurs dans l'enseignement à domicile en Russie pendant la première moitié $d u X I X^{\mathrm{e}}$ siècle]. Avtoref. diss. na soiskanie stepeni kandidata pedagogičeskih nauk [Résumé de la thèse en vue de l'obtention du titre de «candidat ès sciences pédagogiques »], M., 1995 ; Idem, « Pravovoe i material'noe položenie domašnih nastavnikov pervoj poloviny XIX veka » [Statut juridique et situation matérielle des précepteurs à domicile dans la première moitié du XIXe siècle], Istoričeskie zapiski : Mežvuzovskij sbornik naučnyh trudov, Penza, 1998.

4. «Le niveau de connaissances de l'écrasante majorité des étrangers, prétendant à un poste de précepteur ou d'enseignant était si bas [...]», ou encore : "Ceux qui étaient chez eux des palfreniers, des charpentiers, des laquais se faisaient passer en Russie pour des éducateurs et des précepteurs », cité, en traduction, de : S. V. Sergeeva, Častnoe obrazovanie v Rossii, op. cit., p. 30. Voir aussi E. Haumant, La culture française en Russie..., op. cit., p. 86 : l'auteur cite des témoignages recueillis dans les Mémoires contemporains, mais ne les recoupe pas avec des sources plus fiables. Ces Mémoires montrent avant tout qu'il y a une certaine crise de conscience dans la haute société russe ; les prendre comme une vérité absolue sans porter un regard critique serait évidemment incorrect. 
et la bourgeoisie qui veulent donner à leur progéniture les connaissances nécessaires à la vie en société et/ou à l'exercice d'une profession.

Les langues vivantes, et en premier lieu le français, occupent une place importante dans les nouvelles écoles. La naissance de la «République des Lettres », le déclin de la popularité du latin, la renommée grandissante de la littérature française, le développement du commerce des livres, la dissémination des huguenots à travers l'Europe, tout ceci a contribué à augmenter la popularité du français et à rendre son apprentissage indispensable.

En dépit d'un contexte paneuropéen, le système éducatif des pays d'Europe n'était évidemment pas uniforme. La situation des émigrants français, présents dans le domaine éducatif partout en Europe, est conditionnée, dans chaque pays, par les rapports entre l'enseignement public et privé, le contrôle de l'État sur les établissements privés, la concurrence entre le personnel autochtone et étranger, sans parler du statut juridique des étrangers propre à chacun des pays.

Avant de se pencher sur les pensionnats de Saint-Pétersbourg et de Moscou, il convient d'examiner les établissements d'enseignement privé dans d'autres pays européens. En France, les collèges étaient la forme privilégiée pour les écoles primaires et secondaires. Ils étaient tenus par l'Église, ce qui transparaît dans l'enseignement qui y était dispensé : petit nombre de matières, priorité accordée aux langues mortes (surtout au latin), et à l'Histoire Sainte. On reprochait aux collèges de ne pas préparer les enfants à la vie et à l'exercice d'une profession. L'enseignement était alors basé sur la contrainte dont la contestation donna naissance à une nouvelle pédagogie qui commença à se développer dans la deuxième moitié du XVIII ${ }^{\text {e }}$ siècle et se manifesta à travers des ouvrages pédagogiques (JeanBaptiste de la Salle, Charles Rollin, Claude Fleury), des méthodes nouvelles (par exemple, « le bureau typographique » de Louis Dumas) et de nouveaux établissements d'enseignement, notamment les pensionnats.

Les «méthodistes» qui ouvraient les nouvelles écoles entraient ainsi en concurrence avec les collèges. Ils s'appuyaient sur des principes novateurs. L'éducation devait se faire sur la base de l'intérêt, des « sentiments », et non des « mots » comme cela se pratiquait dans les collèges. Cette nouvelle pédagogie avait pour but d'enseigner par la compréhension, l'observation plutôt que par l'exercice de la mémoire, pour donner à l'enfant le sentiment de l'utilité de la connaissance. Les matières enseignées étaient plus variées : d'un côté la musique et la danse, les langues vivantes, la géographie et l'histoire, les «bonnes manières », pour la culture générale et la vie en société ; de l'autre, les sciences exactes (arithmétique, algèbre, géométrie, physique, etc.), la comptabilité, la navigation, le dessin, pour l'acquisition d'une profession particulière. La clientèle n'était pas la même : les enfants de la noblesse et de la grande bourgeoisie dans le premier cas, les enfants de la petite bourgeoisie et des artisans aisés dans le deuxième. Le latin et le catéchisme passaient au second plan. Le nombre de ces 
pensionnats ne cessa d'augmenter et prit un essor particulier dans les années $1770^{5}$.

Les études dont nous disposons permettent d'avoir une vision d'ensemble du développement du système des écoles privées en Europe et de l'implication des étrangers, notamment des Français, dans ce processus ${ }^{6}$. Anna Nikliblorc a étudié la diffusion du français en Pologne au XVIII siècle et les principaux lieux de son enseignement : à domicile, chez les magnats et la noblesse en général, dans les établissements d'État (par exemple, les écoles militaires), et dans les écoles privées. Parmi celles-ci, l'auteur met l'accent sur les écoles confessionnelles : collèges jésuites, visitandins, théatins et enfin, écoles des Piarons. C'est justement dans ces dernières que, grâce à l'abbé Konarsky, en 1740, la pédagogie subit une réforme qui mit de côté le latin au profit des langues vivantes, en premier lieu du français, ce qui répondait aux attentes de la noblesse et de la bourgeoisie aisée. Pour rendre l'enseignement des langues plus efficace, Konarsky insistait sur la nécessité d'engager comme professeurs des natifs de ces langues, il soulignait également l'importance de la pratique en dehors des cours, par le dialogue avec les gouverneurs et les domestiques étrangers pendant le repas ou la promenade. Dans le même temps, les langues vivantes étaient, comme auparavant, considérées comme des disciplines de second plan, qui devaient aider à acquérir les qualités nécessaires à la vie en société, au même titre que la musique et la danse. L'influence de cette réforme se fit sentir également sur les écoles jésuites qui commencèrent à faire plus fréquemment appel aux natifs de la langue et divisèrent le cycle d'enseignement du français en quatre niveaux. Dès le deuxième, on commençait à enseigner l'histoire en français, d'abord l'histoire générale, puis l'histoire de la Pologne ${ }^{7}$. Quelques manuels de français, conçus spécialement à l'intention des Polonais, connurent alors un grand succès ${ }^{8}$.

K. J. Riemens évoque, lui, le grand nombre de pensionnats privés en Hollande au XVIII ${ }^{\mathrm{e}}$ siècle, non seulement dans les grands centres, mais aussi dans les villes petites et moyennes. Les huguenots y jouaient de toute évidence un rôle important : les noms à consonance française sont extrêmement fréquents parmi les directeurs de ces établissements. Il s'agissait, pour une grande part, de descendants de hugue-

5. M. Grandière, L'idéal pédagogique en France au dix-huitième siècle, Oxford: Voltaire Foundation, 1998, p. 93-100, 104-109, 164-165, 168-169, 283-288 ; Histoire générale de l'enseignement et de l'éducation en France, sous la dir. de L.-H. Parias, t. II, par F. Lebrun, M. Venard, J. Quéniart, Paris, 1981, p. 548-557.

6. Voir, par exemple : A. Nikliborc, L'enseignement du français dans les écoles polonaises au XVIII ${ }^{e}$ s., Wrocław, 1962 (Travaux de la Société des sciences et des lettres de Wrocław, Seria A, 83 ) ; K. J. Riemens, Esquisse historique de l'enseignement du français en Hollande du XVI au XIX $X^{\mathrm{e}}$ s., Amsterdam, 1919 ; E. Hammar, L'enseignement du français en Suède jusqu'en 1807. Méthodes et manuels, Stockholm : Akademilitteratur, 1980, et Idem, « La Française » : mille et une façons d'apprendre le français en Suède avant 1807, Uppsala : Almqvist \& Wiksell, 1991 (Uppsala Studies in Education, 41).

7. A. Nikliborc, op. cit., p. 10-12, 26-44.

8. Par exemple, les manuels de français des pères Dabrowski, en polonais, et Wiśniewski, en latin. Voir A. Nikliborc, op. cit., p. 37. 
nots installés en Hollande depuis le XVII siècle. Dans les pensionnats hollandais, on enseignait la « religion protestante », le français et le hollandais, la lecture, l'écriture, l'arithmétique, la géographie, l'histoire et l'on donnait aussi des cours de couture et une formation ménagère aux jeunes filles. En payant un supplément, on pouvait aussi prendre des cours de dessin, de latin, d'italien, de grec ou d'allemand, de danse, d'escrime, etc. Cependant, le français occupait une place prépondérante, on l'apprenait à des fins essentiellement pratiques. En Hollande, le matériel pédagogique pour l'enseignement de cette langue connaît un véritable essor au XVIII ${ }^{\mathrm{e}}$ siècle. À côté des livres « à succès », tel le Restaut, le Des Pepliers, le Girard, le De la Touche, qu'on importe de France ou qu'on imprime sur place, on édite également des «manuels » spécialement dédiés aux élèves hollandais 9 .

En Suède, dès 1724, des mesures sont prises pour limiter l'afflux de professeurs non qualifiés. À cette époque, les Français sont nombreux, mais selon Elisabet Hammar, il est exceptionnel qu'un Français se voie confier la responsabilité de toute l'éducation d'un enfant. Le plus souvent, on fait appel à un étudiant suédois pour l'enseignement, à domicile, des bases de la langue, enseignement que l'on complète par la suite auprès d'un Français d'origine. Les écoles privées dirigées par des Français sont peu nombreuses (le nombre de maîtres de pension français entre

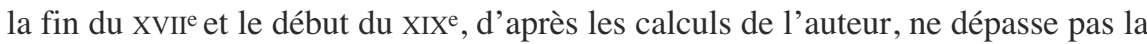
dizaine). Dans le corps enseignant, les Français ne sont pas plus nombreux. Cela est dû, apparemment, plus à l'habitude de faire appel au personnel suédois qu'à la différence de confession. À l'aube du XVIII siècle, les universités suédoises enseignaient le français à un grand nombre d'étudiants (le premier enseignant français apparaît dans les murs de l'université en 1637 à Uppsala). Le français était aussi à l'honneur dans les écoles militaires. Au XVIII siècle, les établissements privés jouent, dans le secondaire, un plus grand rôle que les établissements gérés par l'État. Pour la période allant de la fin du XVII ${ }^{\mathrm{e}}$ au début du XIX ${ }^{\mathrm{e}}$, Elisabet Hammar compte environ 65 écoles privées dont une dizaine sont importantes, comprenant jusqu'à cent élèves, parfois plus, et 6 écoles paroissiales. Le français était la matière principale dans une quinzaine d'établissements. Le corpus des matières enseignées est presque toujours identique : langues vivantes, latin, mathématiques, histoire, géographie, et souvent comptabilité. Les jeunes filles étudiaient, en plus du français, la couture et « diverses matières utiles ». Les directeurs de ces établissements étaient d'origines très diverses. On trouve un ou deux pédagogues expérimentés et faisant figure d'autorité, par exemple le Français Villeneuve que nous rencontrons un peu plus tard en Russie, ancien précepteur de l'héritier du trône de Suède, ou encore Stridberg, professeur d'université, auteur d'un «manuel » de français très populaire en Suède et d'un dictionnaire latin-français. Mais la plupart du temps, il s'agit de personnes n'ayant pas de rapport direct avec la pédagogie comme le Suisse Ferrier, horloger de son état, qui passera en Russie dans les années 1760

9. K. J. Riemens, op. cit., p. 144-223. Voir la longue liste de littérature scolaire éditée à cette époque, en annexe de cet ouvrage. On ne trouve pas d'informations sur le niveau de diffusion de cette littérature et son utilisation dans les pensions. Je donne les références des ouvrages mentionnés dans l'annexe 9, à la fin de cet article. 
pour y pratiquer finalement son premier métier. En dehors du «manuel » de Stridberg, on utilise en Suède le livre de Des Pepliers, mais aussi Les Aventures de Télémaque, Le Magasin des enfants de Madame Leprince de Beaumont et, dans une moindre mesure, les fables d'Ésope, les Lettres à Émilie sur la mythologie de Demoustier et quelques autres livres ${ }^{10}$.

«Une seule chose n'était pas très agréable à mon père, c'est que pour le français, j'avais totalement oublié l'allemand »

A. Bolotov, Žizn'i priključenija ${ }^{11}$

En 1731, le Corps des cadets nobles de l'armée de terre est fondé à Saint-Pétersbourg. Cette école militaire d'État accueillait les fils des familles nobles âgés de 13 à 18 ans. À l'époque, c'est pratiquement la seule institution scolaire pour les nobles. Suivront le Corps des cadets nobles de la marine (1752), le Corps des pages (1757) et quelques autres. Il y avait aussi d'autres établissements d'enseignement public, avant tout le « gymnase » et l' « université » dépendant de l'Académie des sciences (fondée en 1726). Mais la noblesse hésitait à confier ses enfants au gymnase académique ainsi que plus tard à l'université de Moscou'12.

D'après E. Lihačeva, historienne de l'éducation des femmes, les premiers pensionnats étrangers voient le jour en Russie sous le règne d'Elisabeth ${ }^{13}$. En effet, les premières annonces de pensions privées n'apparaissent pas dans le journal Sankt-Peterburgskie vedomosti ${ }^{14}$ avant les années 1740. À Moscou, l'un des premiers pensionnats, fondé dans ces années-là par un nommé Gilquin, Français catholique, n'enseigne apparemment que les langues (russe, allemand, français et latin $)^{15}$.

On peut considérer que le premier pensionnat étranger en Russie au XVIII ${ }^{\mathrm{e}}$ siècle est l'école créée en 1705 à l'initiative du célèbre pasteur Glück. Cependant, il est difficile de qualifier de privé ce pensionnat, car en réalité il est fondé par oukase du tsar et financé par des fonds publics, sous la tutelle de la Chancellerie d'Ijora. Cet établissement se situe entre un pensionnat d'enseignement général et une école

10. E. Hammar, «La Française... », op. cit., p. 11-51. Pour les références complètes des livres mentionnés, le lecteur est invité à se reporter à l'annexe 9.

11. A. Bolotov, Žizn'i priključenja Andreja Bolotova, opisannye samim im dlja svoih potomkov [ Vie et aventures d'André Bolotov décrites par lui-même pour ses descendants], M.L. : Akademia, 1931,t. 1, lettres 10-11.

12. V. O. Ključevskij, «Zapadnoe vlijanie v Rossii posle Petra » [L'influence occidentale en Russie après Pierre [le Grand]], in Idem, Neopublikovannye proizvedenija [Euvres inédites], réd. M. V. Nečkina, M. : Nauka, 1983, chap. 8 .

13. E. Lihačeva, Materialy dlja istorii ženskogo obrazovanija v Rossii, op. cit., t. 1, p. 68.

14. Cité infra : SPbV ; voir Gazeta «Sanktpeterburgskie vedomosti » XVIII veka. Ukazateli $k$ soderžaniju [Le journal «Sanktpeterburgskie vedomosti »du XVIIr siècle, index du contenu], t. 2 : 1732-1735 gg., L., 1989, t. 4 : 1741-1745 gg., L., 1991 ; P. Stolpjanskij n'a découvert que deux annonces d'ouverture de pensionnat privé avant 1750. P. Stolpjanskij, «Častnye školy i pansiony Peterburga... », art. cit.

15. ANF, Mar B7 355. État des Français catholiques romains en Russie en 1746. Je remercie Anne Mézin de m'avoir communiqué ces informations. 
professionnelle: on y enseigne les matières les plus variées, notamment le « maintien corporel », c'est-à-dire la danse, et l'équitation, mais le cœur de l'enseignement est constitué par les langues. Le caractère professionnel de l'école sera plus marqué après la mort du pasteur, survenue en 1705. L'établissement, qui fonctionne jusqu'en 1715, se transforme progressivement en une école de traducteurs ${ }^{16}$.

La première description détaillée d'un pensionnat privé étranger date de la fin des années 1740. Il s'agit des Mémoires du célèbre écrivain et scientifique russe, Andrej Bolotov, qui relatent ses souvenirs de jeunesse ${ }^{17}$.

Bolotov fut confié au pensionnat du Français Daniel Féray, à Saint-Pétersbourg. Celui-ci enseignait également depuis 1749 au Corps des cadets nobles de l'armée de terre, assumant ainsi deux fonctions, probablement pour des raisons financières. C'était pratique courante au XVIII ${ }^{\text {e }}$ siècle ; à l'époque de Catherine II, de nombreux pensionnats étaient tenus par des professeurs de l'université, tel Čebotarev, Chadin, Baudoin, Wille, etc. Au début du XIX ${ }^{\mathrm{e}}$, cette pratique avait encore cours ${ }^{18}$.

La maison où vivait Daniel Féray et qui abritait le pensionnat se trouvait non loin du Corps des cadets, sur l'île Vassilievski. « Mon maître avait alors douze ou quinze élèves, écrit Bolotov, certains étaient pensionnaires, d'autres venaient chaque jour, mais mangeaient et dormaient chez eux ». Il était couramment admis de donner le choix aux parents, de laisser l'enfant en pension complète ou de l'autoriser à rentrer à la maison. De nombreux parents appréciaient la possibilité de laisser leur enfant au pensionnat : le père de Bolotov, par exemple, étant militaire, ne pouvait pas être constamment aux côtés de son fils. Pour l'enfant, la séparation d'avec la famille était sans doute difficilement vécue, mais elle constituait une étape importante dans la socialisation.

« En ce qui concerne ceux qui n'étaient là que dans la journée, c'était très varié, il y avait entre autres une jeune fille déjà grande, dont le père était major ». Apparemment, les pensionnaires étaient tous des garçons, mais parmi les externes on admettait des filles. Par la suite, les pensionnats seront souvent mixtes.

16. Voir la biographie de Glück: $R B S$ [Dictionnaire biographique russe], t. GerberskijGogenloe, p. 391-393. Sur son école : «O nemeckih školah v Moskve pervoj čertverti XVIII veka : 1705-1715: dokumenty Moskovskih arhivov » [Des écoles allemandes dans le Moscou du premier quart du XVIII ${ }^{\mathrm{e}}$ siècle, 1705-1715 : documents des Archives de Moscou], ČOIDR, t. 1, 1907, p. III-XXI, 33-45 ; V. A. Kovrigina, Nemeckaja sloboda Moskvy i ee žiteli v konce $X V I I-$ pervoj čertverti XVIII vV. [Le quartier allemand de Moscou et ses habitants à la fin du XVII -début du $\left.X V I I I^{e}\right]$, M., 1998, p. 313-333.

17. A. Bolotov, Žizn'i priključenia..., op. cit.

18. Opisanie del arhiva Ministerstva narodnogo prosveščenija [Description des archives du ministère de l'Instruction publique], réd. S. F. Platonov, A. S. Nikolaev, S. A. Pereselenkov, 2 t., Petrograd, 1917-1921, t. 1, p. 27 ; Moskovskie Vedomosti (infra - MV), n 2, 1777 ; M. I. Suhomlinov, Issledovanija i stat 'i po russkoj literature i prosveščeniju [Études et articles sur la littérature et l'éducation en Russie), t. 1-2, SPb., 1889, t. 1, p. 77, 106-107, 235 ; A. SaintThomas, Predloženie o zavedenii kommerčeskogo pansiona [Proposition pour la fondation d'un pensionnat commercial], SPb., 1829. Saint-Thomas était enseignant à l'université de Saint-Pétersbourg. 
Le professeur nous donnait peu de leçons parce qu'il devait se rendre chaque jour au Corps des cadets pour enseigner aux cadets, ce qui fait qu'il ne pouvait venir en personne nous donner une leçon qu'une heure à midi et encore une heure le soir. Le reste du temps, c'est l'aîné de ses deux fils qui faisait la leçon. L'un s'appelait Alexandre, il était très grand et pouvait déjà enseigner quand il le fallait et il était très bon, mais l'autre, prénommé Friedrich, était encore jeune, enflammé, remuant et méchant, aucun de nous ne l'aimait à cause de sa vivacité et de sa méchanceté.

On peut envier la mémoire de Bolotov. Daniel Féray avait effectivement deux fils, l'aîné, Alexandre, né en 1732, avait donc à l'époque 18 ans. Le cadet, Friedrich, prénommé plus tard Fëdor, était né en 1741. Cette famille était venue en Russie sans doute sous le règne d'Anna Ioannovna, dans les années 1730. Daniel Féray luimême, bien que fils de Français, n'était pas né en France, mais à Amsterdam ${ }^{19}$, où s'étaient probablement installés ses parents huguenots, fuyant les persécutions religieuses. En Russie Daniel Féray s'engagea d'abord chez les Naryškin, famille de la grande noblesse. Il bénéficia probablement d'une recommandation qui l'aida à entrer au Corps des cadets. « Le très bon » Alexandre, fils aîné de Daniel, deviendra archiviste du collège des Affaires étrangères, quant à son frère «enflammé, remuant et méchant », il fera carrière dans l'armée, combattra dans les troupes russes pendant la guerre de Sept ans, puis dans la guerre russo-turque en 1770. Les enfants des premiers réfugiés huguenots assimilaient la langue et la culture de leur pays d'accueil, et ceux qui s'exilaient une seconde fois - comme les Féray - ne ressentaient plus la même attraction pour leur pays d'origine. La différence confessionnelle ne les poussait pas à établir des contacts avec les Français catholiques, déjà nombreux à Saint-Pétersbourg. À ce propos, dans la première moitié du siècle, la majorité des enseignants français dans la capitale russe, aussi bien dans le privé que dans le public, étaient huguenots. Il était donc naturel que l'un des premiers pensionnats de la ville fût fondé par un Français protestant.

Mais revenons au petit Andrej Bolotov, qui révélait de véritables capacités dans l'étude du français :

Comme j'avais débuté mon apprentissage du français alors que j'étais encore en Courlande, et qu'ici, il ne me restait plus qu'à le prolonger, mes résultats furent tout à fait brillants. Je comprenais si bien et j'étais si studieux qu'en moins de six mois, je dépassai mes camarades de classe et pris la première place de l'école, et en toutes circonstances, je pouvais aider et corriger tout le monde. [...] Notre apprentissage consistait surtout en traductions du russe vers le français des fables d'Ésope et des journaux russes, et cette méthode n'est pas mauvaise : de cette façon, nous apprenions toujours mieux la langue française, et en traduisant les journaux, nous connaissions les styles politique et historique, ainsi que les noms des pays et des villes du monde.

Rappelons que les fables d'Ésope étaient aussi utilisées dans d'autres pays pour l'enseignement du français. Féray n'avait apparemment pas de « manuel » et utili- 
sait ce qu'il avait sous la main : des journaux, probablement les Sankt-Peterburgskie vedomosti, ainsi que des œuvres littéraires accessibles. Dans les dix années qui vont suivre, le matériel pédagogique changera considérablement.

Le père du petit Andrej regrettait certaines orientations de son éducation :

«En ce qui concerne le français, je l'avais assez bien appris pendant toutes ces années, et je pouvais non seulement parler, mais aussi traduire si nécessaire. $\mathrm{Au}$ contraire, $\mathrm{j}$ 'avais presque complètement oublié l'allemand car personne dans notre école ne le comprenait ni ne le parlait, et je n'avais donc de toute l'année aucune occasion de dire un mot à qui que ce soit en allemand, si bien que je le désappris à tel point que je ne savais même souffler mot. Voilà ce que fait le manque d'habitude et de pratique ! je pouvais cependant lire, écrire et comprendre.

Il est intéressant de remarquer que le seul reproche du père de Bolotov à l'encontre du pensionnat concernait l'absence de l'allemand alors que, pour le reste, il était satisfait des progrès de son fils.

Mon père ne manqua point de m'examiner sur toutes mes connaissances. Il était content que j'aie appris quelque chose en français [...] Une seule chose lui fut assez désagréable, c'était que pour apprendre le français, j'avais complètement oublié l'allemand. Afin de compenser ce manque, il me fit donner des leçons d'allemand quelques heures par jour par Müller, mon ancien professeur, qui vivait à la maison, pour rafraîchir ma connaissance de cette langue.

L'inquiétude du père d'Andrej est compréhensible, l'allemand étant à l'époque une langue indispensable au même titre que le français, sinon plus. En effet, si la vie dans la bonne société devenait difficile sans le français, il était inconcevable de poursuivre ses études à l'université en Russie sans connaître l'allemand, les professeurs étant la plupart du temps de langue allemande. Une certaine connaissance du latin et de l'allemand était obligatoire à l'entrée de certains établissements éducatifs ${ }^{20}$.

Le français était au centre de l'enseignement dispensé dans l'école de Daniel Féray. Mais «en ce qui concerne l'histoire, il n'était pas d'usage, dans notre pensionnat, d'enseigner cette matière », écrit Bolotov. On pourrait attribuer un tel désintérêt au manque de littérature pédagogique car il était difficile de se procurer des livres russes, bien plus que des livres français. «Quel dommage, écrit-il, qu'en Russie il y eût alors si peu de livres russes, si bien que dans les maisons on ne trouvait aucune bibliothèque ni la moindre collection, et pas plus dans les maisons des Français ». Mais il existait, sans doute, d'autres raisons à cette absence de l'histoire dans les programmes. Bien que le nombre de matières enseignées chez Féray fût pour le moins réduit, son pensionnat jouissait alors d'une bonne réputation dans la ville. Dans les premières annonces d'ouverture de pensionnats à Saint-Pétersbourg,

20. Voir K. Koh, « Prepodovanie nemeckogo jazyka kak inostrannogo v Rossii XVIII veka » [L'enseignement de l'allemand comme langue étrangère dans la Russie du XVIII'], in Nemcy $i$ razvitie obrazovanija v Rossii [Les Allemands et le développement de l'éducation en Russie], otv. red. G. I. Smagina, SPb., 1998, p. 35-46. 
la géographie, l'histoire et les autres matières générales ne figuraient pas du tout ou étaient mentionnées sous la dénomination commune de «sciences». On peut supposer que la clientèle de ces premiers pensionnats ne ressentait pas encore la nécessité d'apprendre ces matières.

En revanche, les langues étrangères étaient toujours au programme, souvent à côté de la couture ${ }^{21}$. Le français gagne progressivement du terrain : on le parle à la cour, les livres français commencent à être à la mode, de nombreux Français travaillent dans les grandes maisons de la noblesse comme valets de chambre, cuisiniers, coiffeurs, on commence à monter des pièces étrangères jouées par la troupe de la Comédie française, arrivée sous le règne d'Élizabeth, et les voyages à l'étranger deviennent plus fréquents.

« [...] faire subir un examen à tous les Étrangers qui se trouvent dans ce vaste Empire et qui se donnent pour gens capables d'enseigner [...]. »

Extrait d'une lettre du maître de pension Saucerotte à l'Académie des sciences ${ }^{22}$ (1757)

Il est important de connaître la situation de l'enseignement privé à Saint-Pétersbourg dans les années 1750 pour comprendre le sens des nouvelles mesures imposées par le gouvernement à cette époque. Le système éducatif prit progressivement forme vers la fin du règne d'Élisabeth. Il y avait les Corps des cadets nobles de l'armée terre, de la marine et des pages, du génie et de l'artillerie, un gymnase et une université de l'Académie des sciences à Saint-Pétersbourg, une université à Moscou et quelques autres établissements. Parallèlement s'était développé un réseau d'écoles privées, généralement créées par des étrangers ou des paroisses non orthodoxes à Saint-Pétersbourg. De nombreux nobles recevaient une éducation à domicile grâce aux précepteurs étrangers.

La sphère de l'éducation privée était totalement en dehors du contrôle du gouvernement qui n'avait pas la moindre idée du nombre de précepteurs et d'écoles privées, ni du contenu des enseignements ainsi que du niveau de compétence des professeurs. En outre, plusieurs précepteurs exerçaient une sorte de petit commerce dans les maisons qui les hébergeaient (les maîtres de pension faisaient de même), enfreignant ainsi les lois sur le commerce de détail, qui ne pouvait s'exercer qu'en des lieux déterminés et avec les autorisations voulues.

L'année 1757 marqua un tournant dans l'histoire de l'enseignement privé en Russie. Cette année-là, un oukase de première importance imposa de faire subir un examen à tous les enseignants à domicile et aux maîtres de pension. Ceux qui engageaient des précepteurs sans attestation de réussite à cet examen, comme ceux qui ouvraient des pensionnats sans avoir cette même attestation, devenaient passibles de sanction (se traduisant par des amendes ou même par une reconduite hors des frontières de l'empire) ${ }^{23}$. Cette même année, on pouvait lire l'annonce suivante

21. P. Stolpjanskij, « Častnye školy... », art. cit., p. 2.

22. SPFA RAN, f[ond]. 3, op[is']. 9, d[elo]. 78, $\mathrm{f}^{\circ} 3$.

23. Polnoe sobranie zakonov Rossijskoj imperii [Collection complète des lois de l'empire de Russie], SPb., 1830, 1757, n 10724. 
dans les $S P b V$ : «Nous informons les professeurs qui enseignent dans des maisons particulières et qui tiennent des écoles privées qu'ils doivent se présenter les mardis à l'Académie des sciences pour passer un examen »24. À Saint-Pétersbourg, l'examen se passait en effet à l'Académie des sciences, alors qu'à Moscou, il était du ressort de l'université25.

Le maître de pension ou le professeur candidat à l'examen s'adressait par lettre à ces institutions et demandait à passer les épreuves ${ }^{26}$. Ces lettres fournissaient parfois des renseignements sur le candidat, mais plus souvent elle représentaient une forme de « credo pédagogique ». Le candidat indiquait dans quelles matières il souhaitait être examiné. C'étaient les professeurs de l'Académie ou de l'université de Moscou qui examinaient le postulant, chacun donnait son avis à la commission qui prenait sa décision et délivrait l'attestation. La commission se contentait de souligner les lacunes du candidat dans la matière choisie, sa capacité ou son incapacité à enseigner la langue « selon les principes », c'est-à-dire avec explication des règles grammaticales. Parfois, elle se limitait à ces quelques mots : « Cette attestation lui est donnée conformément à sa [du candidat - V.R.] demande ». Certains documents de l'Académie témoignent d'un souci d'adoucir la formulation, pour ne pas handicaper le candidat dès le début de sa carrière. Ainsi, le brouillon de l'attestation délivrée à Louis Pontet qui, d'ailleurs, avait une solide expérience d'enseignement au Corps des cadets, indiquait : «L'examen a montré que [bien qu'on ne puisse dire qu'il soit un professeur parfait - texte barré, V.R.], si quelqu'un souhaite apprendre le français par la seule pratique, ainsi que le font les enfants en bas âge, plutôt que par les règles », il peut engager Pontet ${ }^{27}$. Mais en 1779, l'Académie des sciences renoncera à cette charge. Dans l'annonce publiée à cette occasion dans les $S P b V$, l'Académie tenait à désavouer les précepteurs étrangers qui, ayant passé avec succès l'examen à l'Académie, se présentaient comme appartenant à cette institution ${ }^{28}$. Certains utilisaient la nécessité d'obtenir l'attestation comme argument publicitaire. Un certain Saucerotte reçut l'attestation de l'Académie des sciences et s'empressa dès lors, en septembre 1757, de le proclamer dans ses annonces publiées dans le journal $S P b V$ pour prouver la qualité de l'enseignement dans sa pension ${ }^{29}$.

24. $S P b V, \mathrm{n}^{\circ}$ 39, 1757 (cité dans : P. Stolpjanskij, « Častnye školy... », art. cit., p. 4, tr. du russe).

25. Les procès-verbaux de la Conférence de l'université (le nom donné au conseil administratif de l'université) ont été conservés pour la période allant de 1756 à 1770. Ces documents furent versés au fonds des manuscrits du département des livres anciens de la Bibliothèque de recherche A. M. Gorkij. La majorité d'entre eux ont été édités dans Dokumenty i materialy po istorii Moskovskogo universiteta vtoroj poloviny XVIII veka [Documents et matériaux pour l'histoire de l'université de Moscou dans la deuxième moitié du XVIII siècle], t. 1 : 1756-1764, M., 1960 ; t. 2 : 1765-1766, M., 1962 ; t. 3 : 1767-1770, 1785, M., 1963.

26. Voir un exemple de lettre en annexe $\left(n^{\circ} 1\right)$.

27. SPFA RAN, f. 3, op. 9, d. 78 (1757), f 7, 9. Voir le texte complet de cette attestation en annexe $\left(n^{\circ} 2\right)$.

28. $S P b V, 1779$, col. 335 (cité par P. Stolpjanskij, « Častnye školy... », art. cit., p. 5).

29. $S P b V, \mathrm{n}^{\circ} 70,1757$. 
Mais l'obligation de se soumettre à l'examen n'eut pas d'effet sensible : la commission ne refusait l'attestation pratiquement à personne, quel que fût le niveau du candidat ; il y eut aussi un manque patent de suivi de la part des autorités, et de fait l'oukase tomba vite dans l'oubli.

À la fin des années 1760 , sous le règne de Catherine II, il y eut une nouvelle tentative, tout à fait originale, pour établir un contrôle sur l'éducation privée. L'exemple est intéressant car il ne relève plus du souci d'inventaire, ni de certification des maîtres, ni même du contrôle de la qualité de l'enseignement.

À l'époque, pour ouvrir son pensionnat, un étranger louait habituellement un local, passait une annonce dans la presse et recrutait des élèves, parfois sans même en informer les autorités. L'ouverture de l'établissement du Français Louis Carbonnet suivit une procédure différente ; il fut créé à l'initiative des autorités, et même des plus hautes. Le 29 juin 1768, l'impératrice signe à Peterhof un oukase, par lequel elle ordonne au « Collège d'économie de Saint-Pétersbourg » de « modifier le bâtiment de l'hôtellerie de Kazan » sur l'île Vassilievski à Saint-Pétersbourg, d'affecter 3141 roubles à cette opération, et « ceci fait, d'inscrire cette maison au nom de l'enseignant français Carbonnet pour y tenir une pension afin d'enseigner aux jeunes enfants des deux sexes, et de laisser à Carbonnet l'usage de ce bâtiment tant qu'il continuera d'héberger les enfants et de leur enseigner ». La surveillance de la pension est confiée à «Teplov, conseiller privé » ${ }^{30}$; il s'agit de Grigorij Nikolaevič Teplov, l'un des proches collaborateurs de Catherine II.

Selon les documents, l'impératrice prend cette décision dans le but de donner une éducation aux filles de Philippe-Auguste Delesalle, un colon français arrivé en Russie dans les années 1760. Le Cabinet de l'impératrice verse pour chacune d'elles une somme de 147 roubles par an ${ }^{31}$. Les jeunes filles sont inscrites comme venant « du Cabinet de Sa Majesté Impériale ». On peut s'étonner de l'attention que l'impératrice accorde aux filles d'un obscur Français : Catherine s'intéresse-t-elle tellement à leur destin qu'elle consacre des moyens importants et le temps de ses meilleurs adjoints afin de leur assurer un enseignement et une éducation de qualité ? La création d'une pension sous le contrôle des hautes autorités a sans doute aussi un autre but, probablement plus important aux yeux de la souveraine : avoir, à titre expérimental, un établissement d'enseignement privé où l'éducation suivrait les vœux de Catherine et ne serait pas laissée à la discrétion du maître de pension, comme c'était le cas dans les autres pensionnats de l'époque.

Les épreuves de l'examen s'y déroulaient en présence de G. N. Teplov. Les discours des élèves s'inspiraient d'une certaine image de l'empire, de ses souverains et de sa capitale, qui était en passe de devenir officielle. Teplov écoutait les louanges exaltées chantant « une ville aujourd'hui l'émule d'Athènes, et où sous la protection de la plus grande des souveraines, la prudence, le zèle et la vertu dirigent les arts et donnent de l'éclat aux sciences en formant ces sujets déjà si propres à répondre aux

30. RGADA, f. 17, op. 1, d. 6, $\mathrm{f}^{\circ}$ 1. Je remercie Wladimir Berelowitch d'avoir mis à ma disposition les copies des documents de ce dossier.

31. Ibid., $\mathrm{f}^{\circ} 11$. 
vues supérieures de S.M.I. pour le bonheur de ses peuples et la gloire de son Empire ${ }^{32}$. Les élèves devaient sentir qu'ils étaient appelés à contribuer à la naissance d'une Russie qui «va communiquer à l'Europe des Lumières supérieures à celles qu'elle en a reçues ». En s'adressant à Pierre le Grand, sans toutefois le nommer, l'élève Stakelberg s'exclamait : «O ! Mânes du plus Grand des souverains, si du haut des célestes demeures votre génie bienfaisant pouvoit descendre jusqu'aux choses terrestres, quelle sensation délicieuse n'éprouveroit-il pas en voyant à quel degré de gloire est parvenu ce peuple que vous avez arraché au néant ? ${ }^{33}$. C'est une rhétorique déjà officielle à l'époque. Mademoiselle Delesalle, dans son discours, loue « les grandes vues de S.M.I. pour l'éducation et de ses sujets et des enfants d'étrangers qui ont eu le bonheur de naître dans son Empire $»^{34}$. Faut-il y voir un élan spontané d'une étrangère éduquée aux frais de l'État ou le travail effectué en amont par le directeur du pensionnat et par ses surveillants haut placés ?

L'examen commençait par un discours sur l'utilité de la science, prononcé par les élèves dans les trois langues enseignées au pensionnat. Venait ensuite le moment des épreuves à proprement parler, en géographie, en dessin, en arithmétique, en traduction et en histoire, le tout entrecoupé de récitations de Virgile dont la poésie avait été modifiée : le berger avait été remplacé par la bergère, symbolisant, sans aucun doute, l'impératrice. À la fin, on disait quelques mots sur César, Auguste et d'autres grands personnages de l'Antiquité et le déroulement de l'histoire menait tout naturellement au règne de Sa Majesté Impériale. Le rideau, qui se trouvait au fond, tombait alors dévoilant à l'assistance le buste de l'impératrice encadré du portrait de Pierre le Grand et du buste de Paul Petrovič, héritier du trône. À côté de Paul apparaissait Minerve le menant sur la voie de la Vérité et désignant l'impératrice et Pierre le Grand, qui se trouvaient sur le même plan, éclairés par les rayons du soleil. À la fin du dialogue, on voyait descendre la Gloire, qui posait, sur la tête de l'impératrice, une couronne de lauriers et poursuivait son chemin sur la terre. L'examen s'achevait par un ballet où des bergers louaient les succès des armées de Sa Majesté et lui exprimaient leur amour ${ }^{35}$. L'idéologie du règne y est bien résumée, notamment dans ses rapports à l'Antiquité et à l'Europe occidentale moderne. Catherine II y apparaît en héritière de l'œuvre d'un grand souverain qui arracha la Russie au néant et l'introduisit dans le concert des nations européennes. Le grand-duc Paul, lui, se voit assigner le rôle d'héritier dont la présence montre la stabilité de la dynastie ; il est appelé à continuer l'œuvre de sa mère, mais ne participe nullement de sa gloire.

On peut donc, à notre avis, parler d'une expérience qui avait pour objectif de mettre sous le contrôle du pouvoir l'éducation dans une école privée, et en particulier son contenu idéologique. Saint-Pétersbourg étant une ville cosmopolite où la présence étrangère était forte, le pouvoir cherchait des moyens d'encadrer cette masse d'étrangers, y compris à travers l'éducation. Cette expérience ne fut appa-

32. En français dans l'original. Ibid., $\mathrm{f}^{\circ} 24-25$.

33. Ibid.

34. Ibid., $\mathrm{f}^{\circ} 21 \mathrm{v}^{\circ}$.

35. Ibid., $\mathrm{f}^{\circ} 27$. 
remment pas renouvelée car nous n'avons pas connaissance d'autres cas de ce type. Il est possible qu'elle ait été jugée inefficace. En dépit de son caractère exceptionnel, l'exemple est significatif des tentatives réitérées de mise sous contrôle des écoles privées en Russie.

Manifestement, le problème n'a pas été résolu : lorsqu'il est question, en 1784, d'introduire le programme des écoles publiques dans les pensionnats privés et qu'on veut savoir le nombre de ces derniers et leurs activités, il apparaît que personne ne dispose de ces informations, si bien que les membres de la Commission pour la création d'écoles publiques sont obligés de mener leur propre enquête ${ }^{36}$. Or une inspection des pensionnats de Saint-Pétersbourg par une commission de l'Académie des sciences avait déjà eu lieu en 1780. On peut observer ici un manque de coordination des différentes structures de l'État.

En 1784, nous l'avons dit, une nouvelle tentative de durcir le contrôle sur l'enseignement privé eut lieu. La Commission décida d'introduire des « règles permanentes pour l'établissement de ces pensions à l'avenir ${ }^{37}$. Voici comment elle en résumait l'esprit : «Tous les pensionnats étrangers dépendent de la Direction des écoles publiques allemandes. Toute personne désirant ouvrir une pension sera obligée dorénavant d'étudier la méthode prescrite pour les écoles publiques à l'École publique allemande principale ». En d'autres termes, le maître de pension devait d'abord passer un examen à l'École allemande principale ${ }^{38}$, il devait ensuite demander l'autorisation d'ouvrir un pensionnat à la Commission pour la création d'écoles publiques en passant par le tribunal de police. Avec cette autorisation, il était possible de créer son école, «mais pas autrement que selon le programme décrit par lui [le directeur de pension - V.R.] et approuvé par la Commission ». « Le mode d'enseignement doit se conformer en tout point à celui employé dans les écoles publiques, et qui est prescrit dans le Manuel fourni par la Commission aux maîtres de pension et aux précepteurs ». Afin d'harmoniser tout le système de l'éducation, les pensionnats furent divisés en «inférieurs » et «supérieurs ». Les premiers devaient comprendre un cycle de deux années et correspondre aux deux premières années des écoles publiques, avec l'enseignement des matières suivantes : alphabet, lecture, écriture, arithmétique et catéchisme. Les pensionnats « supérieurs » devaient correspondre à la troisième année, et enseigner l'Histoire Sainte, la morale chrétienne, l'Évangile, l'arithmétique, la grammaire, l'histoire et la géographie abrégées. On n’enseignait pas les langues dans les écoles publiques, l'allemand était introduit à partir de l'école dite «principale », et le français était réservé à l'enseignement particulier. Mais sachant que les enfants d'origine étrangère constituaient la majeure partie des élèves des pensionnats et que les enseignants étaient pour la plupart étrangers, on laissait aux pensions le choix de la

36. RGIA, f. 730 (Komissija ob učreždenii narodnyh učilišč - Commission pour la création d'écoles publiques), op. 1, d. 70 .

37. RGIA, f. 730, op. 1, d. 70. Sur ce sujet, voir aussi Opisanie del arhiva..., op. cit., t. 1, p. 15-16.

38. Glavnaja nemeckaja škola. Et vers la fin du mois de janvier 1785, selon les documents disponibles, la majorité des précepteurs et maîtres de pension avait réussi cet examen. Opisanie del arhiva..., op. cit., t. 1, p. 20. 
langue dans laquelle les cours seraient donnés. Par ailleurs, il était permis d'ajouter de nouvelles matières. On devait aussi, dorénavant, utiliser dans les pensionnats uniquement les manuels agréés par la Commission (cependant, une inspection des pensions de Moscou en 1785 soulignait qu'il était impossible de se les procurer). L'enseignement du russe devenait obligatoire ${ }^{39}$.

La Commission demanda au tribunal de police de Saint-Pétersbourg (SanktPeterburgskaja uprava blagočinija) d'établir la liste des pensions dont l'inspection fut confiée à F. I. Krejdeman, F. I. Jankovič et O. P. Kozodavlev ${ }^{40}$. À Moscou, une commission fut créée par un oukase du 7 octobre 1785 pour examiner les pensionnats, avec à sa tête l'archimandrite Apollos, recteur de l'Académie de Moscou ${ }^{41}$. Nous reviendrons plus tard sur les rapports de ces deux inspections.

Les pensionnats étaient soumis à la Direction des écoles allemandes (Uprava nemeckih učilišč) et au Comité de charité publique (Prikaz obščestvennogo prizrenija), auprès duquel il fallait demander l'autorisation d'ouvrir un pensionnat, mais tous les établissements restaient « sous la tutelle principale de la Commission ». Le maître de pension avait pour obligation d'adresser à cette dernière, outre le programme des cours, la liste des enseignants avec leurs attestations et d'indiquer le prix des études ${ }^{42}$. Toutes ces bonnes intentions ne furent sans doute que très partiellement mises en œuvre. Le contrôle restait malgré tout assez souple : en 1794, Gabriel Delesalle ouvrit son pensionnat privé à Moscou sans disposer d'aucune autorisation ; il ne s'adressa au Comité de charité publique qu'un an plus tard et l'autorisation lui fut délivrée sans difficulté.

Par la suite, la politique restrictive à l'égard des pensionnats continuera de s'appliquer. Dans le premier tiers du siècle suivant, de nouvelles conditions seront imposées aux précepteurs, notamment la connaissance du russe et l'obligation de dispenser les cours dans cette langue; finalement on interdira d'ouvrir un pensionnat éducatif à tout étranger résidant en Russie depuis moins de cinq ans ${ }^{43}$.

39. Pour un résumé de la réforme proposée, voir : RGIA, f. 730, op. 1, d. 70, f ${ }^{\circ}$ 60-63. Voir aussi : Opisanie del arhiva..., op. cit., t. 1, p. 20 ; D. A. Tolstoj, Gorodskie učilišča v carstvovanie imperatricy Ekateriny II [Les écoles urbaines sous le règne de l'impératrice Catherine II], SPb., 1886, p. 88-89.

40. Opisanie del arhiva..., op. cit., t. 1, p. 16.

41. K. V. Sivkov, « Častnye pansiony i školy Moskvy v 80-h godah XVIII v. » [Les écoles et pensionnats privés à Moscou dans les années 1780], Istoričeskij arhiv, n 6, 1951, p. 315-323.

42. A. Voronov, Istoriko-statističeskoe obozrenie..., op. cit., p. 37.

43. RGIA, f. 733, op. 7, d. 199 ; S. V. Roždestvenskij, Istoričeskij obzor dejatel'nosti Ministerstva narodnogo prosveščenija : 1802-1902 [Aperçu historique de l'activité du ministère de l'Instruction publique, 1802-1902], SPb., 1902, p. 76-77. 
Examiner « $[\ldots]$ dans quels endroits et dans quelles maisons ces établissements se trouvent et combien il y a, dans chaque pensionnat, d'élèves de sexe masculin et féminin... » Extrait des dossiers de contrôle des pensionnats privés (1784) ${ }^{44}$

Les documents dont nous disposons permettent d'avoir une idée approximative du nombre de pensionnats en Russie dans la deuxième moitié du XVIII ${ }^{\mathrm{e}}$ siècle. Les dossiers de la commission d'examen de l'Académie des sciences établie en 1757 ne sont pas exhaustifs car ils ne citent que les noms de ceux qui se présentèrent « spontanément »à l'Académie. On compte ainsi neuf personnes qui tenaient un pensionnat en 1757, plus deux autres qui avaient eu un pensionnat auparavant ou qui étaient sur le point d'en ouvrir un. Parmi les maîtres de pension, quatre étaient français, les autres, à en juger d'après le nom, étaient certainement allemands, certains d'entre eux avaient grandi en Russie ${ }^{45}$.

Les inspections générales des pensionnats organisées en 1780 et 1784 à SaintPétersbourg, et en 1785 à Moscou, ne permirent pas de les recenser dans leur totalité. D'après les chiffres communiqués par E. Lihačeva, on comptait 19 pensionnats dans la capitale en 1784, dont 8 étaient tenus par des Allemands, 8 par des Français et 1 par un Russe ${ }^{46}$. Le tableau suivant montre l'évolution du nombre de pensionnats à Saint-Pétersbourg d'après nos propres calculs ${ }^{47}$ (il faut sans doute considérer ces données comme minimales $\left.{ }^{48}\right)$ :

\begin{tabular}{|l|c|c|c|c|c|}
\hline année & $\mathbf{1 7 5 7}$ & $\mathbf{1 7 8 0}$ & $\mathbf{1 7 8 4 ^ { 4 9 }}$ & $\mathbf{1 7 9 4}$ & $\mathbf{1 8 0 0}$ \\
\hline nombre de pensionnats & 9 & 26 & 30 & 22 & 21 \\
\hline dont pensionnats français & 4 & 6 & 9 & 2 & 5 \\
\hline
\end{tabular}

Voici les chiffres pour Moscou ${ }^{50}$ :

\begin{tabular}{|l|c|c|c|c|c|}
\hline année & $\mathbf{1 7 8 5}$ & $\mathbf{1 7 9 0}$ & $\mathbf{1 7 9 3}$ & $\mathbf{1 7 9 5}$ & $\mathbf{1 8 0 0}$ \\
\hline nombre de pensionnats & 11 & 15 & 13 & 16 & 13 \\
\hline dont pensionnats français & 4 & 5 & 6 & 11 & 5 \\
\hline
\end{tabular}

44. RGIA, f. 730 , op. 1, d. $70, f^{\circ} 5$.

45. SPFA RAN, f. 3, op. 9, d. 78 (1757).

46. E. Lihačeva, op. cit., t. 1, p. 257. Il y avait de surcroît 17 écoles russes qui n'étaient pas considérées comme des pensionnats.

47. Exception faite des données pour l'année 1780, tirées de : W. Berelowitch, G. Smagina, « Enseignants et modèles éducatifs français à Saint-Pétersbourg au XVIII siècle », in La France et les Français à Saint-Pétersbourg, XVIII-XX" , Actes du colloque des 24-25 octobre 2003 dans le cadre de l'exposition « Présence française à Saint-Pétersbourg : XVIII-XX' siècles », SPb., 2005, p. 36-69, et notamment p. 48.

48. D'après les documents de la commission de l'Académie des sciences et de la Commission pour la création des écoles publiques.

49. Les données pour l'année 1784 diffèrent légèrement de celles qui ont été publiées par Galina Smagina dans l'article cité, p. 53, sans doute parce que Mme Smagina ne prend en compte que la liste principale des pensionnats (RGIA, f. 730, op. 1, d. 70, f ${ }^{\circ} 6$ ), alors que le même dossier contient quelques compléments ( $\left.\mathrm{f}^{\circ} 7-7 \mathrm{v}^{\circ}, 16-16 \mathrm{v}^{\circ}, 19-22,26-27\right)$. Les Français tenant des pensionnats cette année seraient donc au nombre de neuf.

50. Notons une fois de plus que les données ont été obtenues à partir des documents de contrôle des pensions dont on ne peut garantir l'exactitude. 
D'après les sources dont nous disposons ${ }^{51}$, dans la deuxième moitié du XVIII ${ }^{\mathrm{e}}$ siècle seulement, on compte près de 90 écoles privées différentes à SaintPétersbourg, dont un tiers environ sont ouvertes par des émigrants francophones ${ }^{52}$. En réalité, nous l'avons dit, elles sont sans aucun doute plus nombreuses. Nombre d'entre elles fermaient aussi vite qu'elles avaient ouvert, leur durée de vie étant généralement de quelques années, voire de quelques mois. Les pensionnats français, eux, avaient une durée de vie relativement longue. À Moscou, une dizaine d'établissements français fonctionnèrent pendant cinq ans ou plus, alors que, parmi les autres pensionnats, seulement quatre ou cinq subsistèrent aussi longtemps.

Il est intéressant de comparer ces chiffres avec ceux d'autres pays. Si en Hollande, au XVIII siècle, les Français (le plus souvent des huguenots ou leurs descendants) tenaient pratiquement la moitié des écoles privées, en Russie ils occupaient une place plus modeste, alors que le nombre de précepteurs huguenots, relativement important dans la première moitié du siècle, se réduisit progressivement. Il faut aussi tenir compte de la place très importante de la communauté germanophone en Russie, en particulier à Saint-Pétersbourg et à Moscou, des rangs de laquelle étaient issus un grand nombre d'enseignants. On peut y voir une similitude avec la situation en Suède, à la fin du XVII et au début du XVIII ${ }^{\mathrm{e}}$ siècle, où les Allemands jouèrent aussi un rôle important dans l'éducation, avant d'être remplacés par des professeurs autochtones ${ }^{53}$.

En 1794 l'effectif global des pensionnats de Saint-Pétersbourg atteignait 592 élèves (391 garçons et 201 filles), en 1800 - 685 élèves (dont 410 garçons et 275 filles). Cette augmentation est due aux dimensions que prennent certaines écoles qui comptent parfois une centaine d'élèves. À Moscou, en 1793, 407 élèves (294 garçons et 113 filles) fréquentaient les pensionnats ${ }^{54}$.

On peut remarquer que la part des effectifs féminins augmente progressivement. Sous le règne d'Alexandre ${ }^{\mathrm{er}}$, les pensionnats mixtes (forme privilégiée au XVIII ${ }^{\mathrm{e}}$ siècle) sont interdits. Voici les chiffres pour le premier tiers du siècle suivant (pensions de Saint-Pétersbourg) :

\begin{tabular}{|l|c|c|c|}
\hline année & $\mathbf{1 8 2 0}$ & $\mathbf{1 8 2 4}$ & $\mathbf{1 8 2 8}$ \\
\hline nombre de pensionnats pour garçons & 20 & 19 & 17 \\
\hline nombre de pensionnats pour filles & 25 & 30 & 45 \\
\hline
\end{tabular}

51. Voir en annexe la liste des directeurs d'écoles privées à Saint-Pétersbourg dans la deuxième moitié du XVIII' siècle ( $\left.\mathrm{n}^{\circ} 7\right)$.

52. Voir aussi la liste des maîtres de pensionnats privés à Moscou dans la deuxième moitié du XVIII' siècle (annexe 6).

53. Comparer avec les travaux déjà cités de E. Hammar et K. J. Riemens.

54. Sur la base de l'analyse d'une série de dossiers issus du fonds de la Commission pour la création d'écoles publiques (RGIA, f. 730), et des documents fournis par l'article déjà cité de K. V. Sivkov, («Castnye pansiony...»), et aussi dans Opisanie del arhiva..., op. cit., et A. Voronov, Istoriko-statističeskoe obozrenie..., op. cit. 
En 1828 l'effectif global atteint 1644 élèves à Saint-Pétersbourg. En province, l'enseignement privé se développe plus lentement : à Arkhangelsk, on ne compte que deux pensionnats en 1816 et à Pskov un seul (pour filles) en 182455 .

Ce pensionnat « [...] convient particulièrement aux Secrétaires employés [...] auprès des Ambassadeurs, ou Envoyés dans les Cours étrangères » Extrait de la lettre de Saucerotte, maître de pension, à l'Académie des sciences $(1757)^{56}$

En 1766, Nicolas de Zeemilière (?) annonce dans les $M V$ l'ouverture de son école privée. Zeemilière commence ainsi son annonce : «Les personnes voulant enseigner à leurs enfants la connaissance de Dieu et la vie honnête peuvent s'adresser au prêtre Petr Alekseev de la cathédrale de l'Assomption et de l'Université impériale de Moscou (maison sise à Bersenevka, sur le fleuve Moskova) ${ }^{57}$. Les parents qui souhaitent éduquer leurs enfants dans la crainte de Dieu y trouveront un précepteur français dont ils n'ont rien à redouter car il travaille sous les auspices de l'Église, coude à coude avec le prêtre : « Le précepteur français Nicolas de Zeemilière enseignera à ses élèves le français et l'allemand, ainsi que les bases de l'Histoire et de la Géographie et les parents pourront choisir de confier leurs enfants seulement dans la journée ou de les laisser en pension avec un jour de repos le dimanche à la maison. Cette école privée accueillera des élèves de tout rang, en particulier les fils de commerçants qui ont peu d'occasions de donner à leurs enfants les bases solides de l'enseignement du catéchisme et encore moins de leur apprendre les langues étrangères et les sciences libres ${ }^{58}$. D'autres maîtres de pension cherchaient à attirer les commerçants souhaitant scolariser leurs enfants : 1'Allemand NickolausHeinrich Baman annonçait, en 1779, son intention de créer une «Académie des commerçants à l'exemple de celle du professeur Bisch [?] à Hambourg » et d'y enseigner l'allemand et le français, la lecture et l'écriture, l'arithmétique et « les comptes de commerce $»^{59}$.

Cette attention particulière pour la clientèle des commerçants s'explique par le fait que cette couche de la société, se trouvant de plus en plus en contact avec l'étranger, commençait à exprimer le besoin d'apprendre les langues étrangères, l'arithmétique et d'autres matières nécessaires à l'exercice de leur métier. Rappelons que, dans les pays d'Europe occidentale, la bourgeoisie marchande était déjà, à l'époque, cliente des écoles privées. Pour les maîtres de pension, cette niche du marché était prometteuse. Il n'est donc pas étonnant que Zeemilière s'adresse « en particulier » aux commerçants (et aux commerçants russophones car l'annonce est publiée en russe). La référence à l'enseignement du catéchisme («Loi chrétienne »

55. E. Lihačeva, op. cit.; Opisanie del arhiva..., op. cit.; A. Voronov, Istoriko-statističeskoe obozrenie..., op. cit.

56. SPFA RAN, f. 3 , op. 9, d. 78, f $^{\circ} 5$.

57. $M V, 1766, \mathrm{n}^{\circ} 92$. Trad. du russe.

58. Ibid.

59. RGIA, f. 730, op. 1, d. 70, fo 21. 
ou «Loi Divine ») est naturelle : les commerçants étaient très dévots, le maître de pension comptait donc sur le succès de cet argument. D'autres annonces mentionnent l'intervention de prêtres : en 1770, à Moscou, mademoiselle Guimon-Demorat (?), qui, selon ses dires, avait tenu pendant 25 ans une école en France pour «l'enseignement parfait de la jeunesse », accueillait un «prêtre expérimenté » («iskusnyj svjaščennik») deux fois par semaine ${ }^{60}$. Il en était de même chez Benjamin Guinche : en 1773, le prêtre venait à son pensionnat les mercredis et les samedis $^{61}$.

L'éducation religieuse était loin d'être de règle à cette époque dans les pensionnats privés. Franz von Eisen ${ }^{62}$, qui tenait un pensionnat privé à Moscou en 1785 , expliquait que la «Loi Divine » n'était pas dispensée chez lui n'étant demandée ni par les parents, ni par les autorités. La commission présidée par un ecclésiastique fut scandalisée :

Il convient de confirmer à ce maître de pensionnat comme à tous les autres qu'afin de répondre aux vœux pieux de S.M.I. exprimés dans cette ordonnance, ils doivent enseigner le catéchisme aux enfants, en invitant à cette fin des prêtres savants ou des professeurs de l'Académie ecclésiastique de Moscou, dont l'expérience pédagogique et la bonne conduite sont attestées ${ }^{63}$.

Les 25 élèves de von Eisen, qualifiés de «bien nés » ${ }^{64}$, étaient certainement des enfants de la noblesse qui ne recherchait pas l'enseignement religieux dans les pensionnats. On peut supposer que c'était la principale différence entre la clientèle noble et la clientèle commerçante des pensionnats.

Parfois les documents indiquent clairement à quel public s'adresse l'établissement. Ainsi, au moment de passer l'examen d'attestation, le Français Saucerotte évoque l'enseignement du style épistolaire français qui convient particulièrement aux secrétaires d'ambassade et de missions diplomatiques. Plus loin, Saucerotte parle directement de son intention de s'adresser à une clientèle noble : « Le remontrant qui a acquis un grand usage du beau monde ose aussi se flatter d'être en état de donner une noble éducation aux jeunes cavaliers $»^{65}$. Cependant, la plupart $d u$ temps, la clientèle visée n'est pas précisée ou alors d'une manière voilée, comme dans l'annonce d'un certain Parat, Français, publiée en 1770 dans les $M V$ : chez lui, les enfants sont « éduqués à la manière qui convient à leur condition ${ }^{66}$.

60. $M V, 1770, \mathrm{n}^{\circ} 77$

61. $M V, 1773, \mathrm{n}^{\circ} 16$.

62. Qui est dit français dans les documents, bien que son nom de famille ne le laisse pas deviner.

63. K. V. Sivkov, « Častnye pansiony ... », art. cit. Trad. du russe.

64. Ibid.

65. SPFA RAN, f. 3, op. 9, d. $78, \mathrm{f}^{\circ} 3,33$.

66. $M V, 1770, \mathrm{n}^{\circ} 100$ (trad. du russe). 
Certains maîtres de pension font preuve d'inventivité dans leur façon d'attirer la clientèle. Le Français Samuel Martin met en avant, comme gage de la qualité de son enseignement, le nom de Philippe-Heinrich Dilthey, savant et enseignant de l'université de Moscou, « sous la surveillance duquel les matières suivantes seront enseignées » (suivait la liste des matières) ${ }^{67}$. Champognolot (ou Champogniolot) propose à Moscou en 1768 un prospectus de présentation de son pensionnat, sans doute imprimé68, tout comme Jean-Théophile de Challes qui édite, lui aussi, une brochure pour son établissement en français, en allemand et en russe ${ }^{69}$.

Ces prospectus, si l'on ne tient pas compte de leur caractère publicitaire, donnent malgré tout un aperçu des idées pédagogiques des maîtres de pension. De Challes commence par décrire le local loué pour son pensionnat : une grande et vaste maison située après le pont Anichkov, sur la perspective Nevski, la principale artère de la ville, dans un endroit commode, où les enfants peuvent jouer en plein air. Suit un passage louangeur à l'adresse de Catherine II, dont le règne représente une époque de Lumières pour la Russie, ce que prouve la création de quelques «établissements immortels pour l'éducation nationale ». De Challes compte manifestement sur l'effet de cette rhétorique habituelle. Le maître de pension évoque aussi la nourriture saine, les exercices physiques et la nécessité d'adapter l'éducation au niveau de développement de l'enfant. Suit une liste imposante de matières enseignées et de Challes termine son prospectus en exposant le but de son établissement : apprendre aux élèves la morale et le respect de la religion et des têtes couronnées, en faire des sujets fidèles et de bons citoyens.

On trouve dans d'autres annonces des éléments comparables qui laissent entrevoir qu'un certain type de discours éducatif devient habituel, et sans doute attendu par la clientèle. Antoine Gaillard (?) parle d'un enseignement « méthodique », et de l'accueil d'élèves d'une tranche d'âge restreinte (de 3 à 10 ans) afin « de préserver la pureté de mœurs des enfants qui lui sont confiés ». Comme Challes, Gaillard évoque une nourriture saine et abondante, « adaptée à l'âge et à la constitution des enfants $»^{70}$. On observe une tendance générale à vouloir prendre en compte l'âge et le niveau de développement de l'enfant pour une meilleure éducation physique, morale et intellectuelle.

On peut noter à quel point ce credo pédagogique est proche de l'éducation humaniste qui était à la mode alors en France. Nous trouvons sensiblement les mêmes éléments dans l'annonce de «l'Académie des enfants » tenue en 1755 par les pédagogues français Viard et Mahaux : leurs préoccupations portent sur la santé (il est aussi question de nourriture saine et d'air frais), sur l'adaptation de l'éduca-

67. $M V, 1770, \mathrm{n}^{\circ} 80$.

68. $M V, 1768, \mathrm{n}^{\circ} 22$.

69. «Avis au public sur un établissement pour l'instruction de la jeunesse, de l'un et de l'autre sexe, approuvé par l'Académie impériale des sciences. Dirigé par le Sieur Jean Théophile de Challes, Saint-Pétersbourg, $1772 »$. Le texte de ce prospectus a été reproduit par W. Berelowitch et O. Medvedkova, Histoire de Saint-Pétersbourg, op. cit., p. 207-208.

70. $M V, 1792,27$ octobre-3 novembre. Cette annonce figure in extenso en annexe $\left(\mathrm{n}^{\circ} 5\right)$. 
tion au stade de développement de l'enfant, sur les connaissances à la fois « plaisantes et utiles », etc. On insiste également sur le nombre de matières enseignées ${ }^{71}$. Les précepteurs travaillant en Russie nous ont laissé très peu de témoignages de ce genre. Le maître de pension Saucerotte parle de la nécessité de « former l'esprit et le cœur de son Elève et [de] le contenir dans les voies que la raison et la justice lui prescrivent ${ }^{72}$. Le précepteur Desessart emploie des expressions similaires : « former le cœur à la vertu en ornant son esprit de quelques unes de ces connaissances utiles qui caractérisent l'honneste homme, l'homme aimable et le bon citoyen $\gg^{73}$. On voit ainsi qu'un certain modèle éducatif français, désormais européen, fait son chemin en Russie à travers ce genre d'écoles ${ }^{74}$.

Le public visé par les directeurs de pensionnats était-il celui qu'on retrouve sur les bancs des écoles privées ? Très peu de listes d'élèves de pensionnats privés nous sont parvenues, et ce n'est guère étonnant : les autorités ne les exigeaient pas, et c'est la raison pour laquelle on trouve rarement ce genre de document dans les Archives publiques. Le pensionnat du Français Louis Carbonnet, fondé à l'initiative des autorités, est exceptionnel sous ce rapport car ses documents furent versés aux Archives de la cour. Étant donné le statut spécifique de cet établissement, on peut supposer que ses élèves venaient de couches sociales plus élevées que la moyenne dans ce genre d'établissement.

La majeure partie de ses élèves étaient enfants de fonctionnaires (De Wergert et Abrahomov, secrétaires du collège de Justice, Naumov, secrétaire du SaintSynode, Merillo, économe du Corps des cadets, Schütern, architecte de ce même Corps), ou de militaires de divers rangs (officier subalterne, capitaine, major, lieutenant, le brigadier Alekseev, le général Du Molina), d'artisans aisés (l'horloger Fazi ou Fazy, le bijoutier Koeping), de médecins (les enfants du docteur Enič* et ceux du chirurgien Breling), de courtiers (Sismar et Barz, courtiers près la cour), de marchands et de fabricants (comme le marchand de vin Wenn et le fabricant Boucher, ou les quatre enfants de la famille Demidov), des tailleurs Schmiez (?) et Laurin, du jardinier à la cour Eckleben (qui « ne paie pas en argent »). On trouve aussi parmi les élèves des enfants de gouvernantes, de « secrétaires » (on en compte trois) et d'un « conseiller $»^{75}$.

Notons d'abord que le noyau des élèves (au moins 35 sur 60) était formé d'étrangers (leur niveau d'intégration dans la société russe est un sujet à part). Parmi eux, 12 ou 13 venaient de familles françaises. Ces chiffres correspondent aux données

71. M. Grandière, L'idéal pédagogique en France..., op. cit., p. 164-168.

72. SPFA RAN, f. 3 , op. 9 , d. $78, f^{\circ} 3$.

73. Ibid., $\mathrm{f}^{\circ} 44$.

74. Sur les «modèles éducatifs français » et leur réception en Russie, voir la contribution de W. Berelowitch in : W. Berelowitch, G. Smagina, «Enseignants et modèles éducatifs français à Saint-Pétersbourg au XVIII' siècle », op. cit., p. 61-63.

75. Il s'agit peut-être du rang, consigné par une personne peu au courant de la table des rangs russes, ou bien de la dénomination d'un poste, voir plus bas. 
qui nous sont connues (bien qu'approximatives), et qui dénombrent, en 1780, environ 500 élèves dans les pensionnats, dont seulement 200 russophones.

L'origine sociale des clients de ce pensionnat n'est pas homogène : d'un côté, des enfants d'officiers subalternes, de l'autre, ceux d'un général et d'un brigadier, ou bien du vice-président de la Chancellerie de tutelle des étrangers, des représentants de la grande famille de la noblesse Gudovič ${ }^{76}$ ou encore d'une famille étrangère haut placée à la cour comme la famille Stakelberg77. La présence de la couche supérieure de la noblesse et des fonctionnaires doit sans aucun doute être attribuée au caractère exceptionnel de cet établissement placé sous la protection de l'impératrice car en général les enfants de l'élite étaient plutôt instruits à domicile ${ }^{78}$.

Wladimir Berelowitch ${ }^{79}$ remarque très justement que beaucoup de ces noms sont liés à la Chancellerie de tutelle des étrangers dirigée par Grigorij Orlov, favori de l'impératrice. On y trouve en effet Baskakov, vice-président de la Chancellerie, mais aussi Rezanov, Boucher, l'horloger Fazi, subventionné par la Chancellerie. Ajoutons à cette liste les Delesalle, colons et recruteurs bien connus de la Chancellerie de tutelle. Cependant, on ne peut être certains que toutes ces personnes soient devenues clients de Carbonnet du seul fait de leur lien avec la Chancellerie, et donc avec le trône. L'attention de l'impératrice pour les Delesalle peut également s'expliquer par le fait que des membres de cette famille servaient chez le comte P. B. Šeremetev (1713-1788), général en chef, grand chambellan, seigneur richissime et estimé de l'impératrice ${ }^{80}$.

La proximité avec la cour peut également expliquer la présence d'autres personnes dans cette liste : l'Allemand Heinrich (en Russie, « Andrej ») Eckleben (décédé en 1777 à Saint-Pétersbourg) était, depuis 1762, le jardinier principal des jardins impériaux de Saint-Pétersbourg. Il est l'un des fondateurs de la Société impériale libre d'économie ${ }^{81}$. Le docteur Enič̌ était médecin à la Société d'éducation des jeunes filles nobles, dont les pensionnaires étaient les protégées de l'impératrice $^{82}$. Il en est de même du courtier à la cour. La présence des enfants de la gouvernante des comtesses Razumovskij ${ }^{33}$ est très logiquement due à Teplov :

76. Il s'agit certainement des neveux d'Ivan Vasilievič Gudovič (1732-1821), plus tard comte et général feld-maréchal.

77. Il s'agit sans doute du fils aîné d'Otton Magnus Stakelberg (1736-1800), baron, plus tard comte, diplomate russe, envoyé et ministre plénipotentiaire de Russie en Pologne.

78. Mais voir infra.

79. Remarque recueillie lors de la préparation de cet article pour publication.

80. MAE, Correspondance politique, Russie, vol. $81, \mathrm{f}^{\circ} 300$, etc.

81. P. N. Stolpjanskij, « Staryj Peterburg. Sadovnik Eckleben i pervaja škola sadovodstva » [Le Vieux Pétersbourg. Le jardinier Eckleben et la première école de jardinage], Vestnik sadovodstva, plodovodstva i ogorodničestva, $\mathrm{n}^{\circ} 5,1914$. Je remercie pour leur aide W. Berelowitch et A. Reyman, directeur du service de l'architecture paysagère du Comité des monuments historiques de Saint-Pétersbourg (KGIOP, SPb.).

82. Je remercie W. Berelowitch pour ces informations.

83. Ces comtesses sont probablement les filles du comte Kirill Grigor'evič Razumovskij, ancien hetman d'Ukraine et président de l'Académie des sciences. 
chargé de la surveillance de ce pensionnat, G. N. Teplov avait été un temps au service de Kirill Grigor'evič Razumovskij, qu'il accompagna pendant son voyage à l'étranger de 1743, il fut chargé ensuite de la direction de sa chancellerie en Ukraine (il est vrai que leurs relations se sont détériorées par la suite). On notera également le cercle du collège de Justice, avec Abrahomov, déjà cité, De Verger et, sans doute, De Cabri ${ }^{84}$.

On y trouve aussi, comme nous l'avons vu, des commerçants et des fabricants d'origine très diverse (bien qu'il ne semble pas y avoir de petits commerçants), par exemple les enfants Demidov ${ }^{85}$, une famille d'industriels richissimes qui avaient été anoblis. Leur présence dans ce pensionnat français n'est pas un hasard : l'ascension sociale des Demidov s'accompagnait d'un intérêt accru pour l'éducation et l'art ; cette famille donnera les premiers mécènes russes. Boucher possédait une fabrique de tabac à Saint-Pétersbourg86, et Conrad-Marc Fazi, originaire de Genève, comptait parmi les horlogers les plus importants de Saint-Pétersbourg, possédant plusieurs ateliers et recevant des commandes de la cour ${ }^{87}$. Notons que ce cercle se recoupe avec celui de la Chancellerie de tutelle.

Ainsi, ce pensionnat accueillait un public d'origine sociale élevée, mais aussi des élèves d'origine relativement modeste. Cette mixité n'était sans doute pas voulue, mais il convient de la souligner car il n'existe aucun autre exemple similaire dans les établissements publics de l'époque : à l'Institut Smolny, au lycée (gimnazija) de l'université de Moscou, qui accueillaient des roturiers, les nobles étudiaient à part.

Cet exemple confirme au moins une remarque faite plus haut à propos de la clientèle de haute extraction qui normalement ne fréquente pas les pensionnats éducatifs. Nous ne connaissons que deux autres exemples où cette règle est transgressée, mais la nature des établissements concernés en explique la raison : il s'agit de l' « Académie de la Xe ligne » et de l'institut de l'abbé Nicolle, dont nous parlerons plus tard. Le premier est l'école fondée dans les années 1763-1764 pour les enfants de plusieurs hauts dignitaires russes : des comtes Aleksej, Pëtr et Andrej Razumovskij, fils du comte hetman de l'Ukraine K. G. Razumovskij, les enfants de G. N. Teplov (adjoint de Razumovskij dont nous avons déjà parlé), du comte A. V. Olsuf'ev, secrétaire d'État de Catherine II, et d'A. Kozlov. Dans une maison louée à cet effet sur l'île Vassilievski, ces enfants reçurent l'enseignement de l'adjunkt de l'Académie des sciences russe S. I. Rumovskij, du célèbre historien

84. La liste indique «conseiller», mais nous ne connaissons qu'un seul «conseiller De Cabri », il s'agit d'Isaac Théodore, huguenot, qui représentait l'Estland, la Livonie et la Finlande au collège de Justice entre 1759 et 1764, il était fonctionnaire au service de l'État. J. Kämmerer, Russland und die Hugenotten im 18. Jahrhundert (1689-1789), Schriften zur Geistesgeschichte des Ostlichen Europa, Wiesbaden, 1978, p. 65, 109, 110 ; Russkoe služiloe dvorjanstvo vtoroj poloviny XVIII veka [La noblesse russe au service de l'État, seconde moitié du XVIII S.], sost. V. N. Stepanov, SPb. : Akademičeskij proekt, 2003, p. 264.

85. Il n'est pas aisé de savoir ici de quels enfants il s'agit : on peut supposer qu'il est question des enfants d'Evdokim Nikitič Demidov (1713-1782), directeur d'usine.

86. $S P b V, 5.12 .1774,30.12 .1774$.

87. RGADA, f. 283 , op. 1, d. 16, f ${ }^{\circ} 1-2$; RGIA, f. 1329 , op. 2, d. $70, f^{\circ} 19$. 
A.-L. Schlözer, d'un jésuite de Vienne, d'un Français nommé Bourbier et d'autres professeurs. Le budget de l'établissement (très important, près de 10000 roubles par an) était assuré par le comte Razumovskij. L'inspection de la pension fut confiée à l'académicien et bibliothécaire de l'Académie russe I. K. Taubert. Schlözer participa à la conception du programme des études et insista pour qu'on y inclût la géographie et « la connaissance de la patrie » (la statistique) ; il prépara même de petites brochures, contenant l'abrégé des études que chaque élève devait poursuivre. Ces brochures furent intitulées «à l'usage de l'Académie de la $\mathrm{X}^{\mathrm{e}}$ ligne » [de l'île Vassilievski, où se trouvait cette « académie »]. Schlözer conçut de la même façon une brochure sur la géographie et la statistique russes, rédigée pour la première fois sur la base de sources officielles. Cette brochure acquit très vite une certaine popularité, elle fut très utilisée dans les cours du gymnase de l'Académie des sciences, ainsi que par plusieurs précepteurs étrangers. Bourbier enseignait le français et l'histoire avant d'être remplacé dans cette dernière discipline par Schlözer. On utilisait dans les cours d'histoire les livres d'un historien prussien connu, Hilmar Curas ${ }^{88}$, avant que Schlözer ne se mît à élaborer son propre cours d'histoire. L'historien fut aussi chargé du cours de latin ${ }^{89}$.

Cette expérience est sous certains aspects différente des écoles fondées par des particuliers étrangers, d'abord et surtout parce que l'initiative ici revient à quelques dignitaires russes proches du trône qui organisent le pensionnat et forment le corps professoral. Cela trahit l'intérêt grandissant de la couche supérieure de la noblesse pour une éducation de qualité, qu'il était difficile d'avoir à domicile et qu'on allait chercher à l'étranger dans les villes universitaires (Strasbourg, Göttingen, Leyde, Genève, etc.). Remarquons aussi la présence d'un jésuite parmi les enseignants, trait qui nous donne la mesure de la distance prise par une partie de ce milieu vis-àvis de l'orthodoxie ; notons aussi la présence du latin parmi les matières enseignées, presque inconnu alors dans les pensionnats et très peu enseigné dans les établissements éducatifs d'État ; ou encore celle de la « connaissance de la patrie » qui montre les préoccupations «patriotiques » de cette couche qu'on considère souvent comme européanisée à outrance. Il convient cependant de noter aussi quelques traits communs avec les pensionnats étrangers : le corps professoral est pour une large part composé d'étrangers, même s'ils sont triés sur le volet ; l'enseignement s'appuie, semble-t-il, sur la littérature utilisée dans les pensionnats ordinaires (notamment les livres de Curas, bien connus des maîtres de pension), du moins dans un premier temps, avant la création de cours originaux pour certaines disciplines.

88. Einleitung zur Universal-Historie... Neunte Auflage. Mit einer kurzen Einleitung in die sächs. Historie, etc. Berlin, 1751, 366 p. in- $8^{\circ}$ (nombreuses éditions) ; cette histoire fut traduite et éditée en russe sous le titre : Gilmara Kurasa sokraščennaja universal'naja istorija, SPb., $1747,1762,1793)$.

89. RBS, vol. Pritvic-Rejs, p. 436 ; S. M. Solov'ev, Istorija Rossii s drevnejših vremen, t. 26, ch. 3 . 
Ce précepteur « [...] se trouve en état d'enseigner méthodiquement » Extrait d'une lettre du maitre de pension Saucerotte à l'Académie des sciences $(1757)^{90}$

Les pensionnats n'étaient pas que des écoles pour les enfants. Saucerotte (1757) offrait aussi des services de rédaction de lettres dans les trois langues enseignées dans son établissement, et vendait des livres. Une telle diversité était dans l'air du temps : le pensionnat d'un certain Stillau (?) faisait fonction à la fois d'école et de librairie $^{91}$. Le commerce de livres était souvent pratiqué par des étrangers, mais c'était pour eux généralement une activité annexe ou même occasionnelle ${ }^{92}$.

Saucerotte dispensait ses cours de $9 \mathrm{~h}$ à $12 \mathrm{~h}$, puis de $15 \mathrm{~h}$ à $18 \mathrm{~h}$. Chez Carbonnet (1769), les pensionnaires se levaient à 6 heures du matin, certains allaient à la prière, ensuite tous déjeunaient d'un morceau de pain et de deux tasses de thé. Les élèves étaient en classe de $8 \mathrm{~h}$ à $12 \mathrm{~h}$, puis prenaient un déjeuner avec entrée, plat et dessert, suivi d'un repos jusqu'à 14 h. Ils étaient à nouveau en classe de 14 h à 18 h. Les matières comme le clavecin ou le dessin étaient enseignées dans l'après-midi. Venait le goûter, composé, comme le matin, de pain et de thé, puis les élèves disposaient de temps libre jusqu'à 19 h. Ils faisaient alors leurs devoirs pour le lendemain, puis à 20 h, dînaient d'une entrée et d'un plat. Après le dîner, on allait prier puis on se couchait à $21 \mathrm{~h}$ précises. On retrouve pratiquement les mêmes horaires dans tous les pensionnats en 1784 : des leçons de $8 \mathrm{~h}$ à 11 ou $12 \mathrm{~h}$, puis à 14 h jusqu'à 17 ou $18 \mathrm{~h}^{93}$.

Les matières enseignées étaient à peu près les mêmes d'un pensionnat à l'autre : le français, l'allemand, la grammaire et l'orthographe russes, l'arithmétique, la géométrie, l'histoire, la géographie, le dessin, le catéchisme. La Bible n'était pas étudiée partout, loin s'en faut. Dans le pensionnat de De Forges (ou Desforges), ouvert à Moscou en 1785, on enseignait la géographie, l'histoire, le français, l'allemand, le russe, l'arithmétique et la géométrie. Chez Saucerotte, l'éventail était encore plus large : en plus des matières habituelles, la "sphère ${ }^{94}$, la mythologie, l'héraldique, les bases du latin, la «vraie prononciation », le goût et même la «pureté de la langue ». Si Féray, à la fin des années 1740, ne passait pas d'annonces pour son établissement, dix ans plus tard, Saucerotte fait la publicité de son pensionnat, et met en avant le nombre important des matières enseignées. Les maîtres de pension prenaient très probablement en compte les goûts d'un public toujours plus éclairé et plus exigeant ${ }^{95}$. Mais dans le pensionnat d'un certain de

90. SPFA RAN, f. 3 , op. 9 , d. $78, \mathrm{f}^{\circ} 3$.

91. $S P b V, \mathrm{n}^{\circ} 9,1765$.

92. V. Somov, «Le livre français à Saint-Pétersbourg au XVIII ${ }^{e}$ siècle », Les Français à SaintPétersbourg. Catalogue de l'exposition, SPb., 2003, p. 76-79.

93. RGIA, f. 730, op. 1, d. 70, f 52 .

94. Il s'agit probablement de la « sphère terrestre » ou l'étude du globe terrestre.

95. Gazeta «Sanktpeterburgskie vedomosti »XVIII veka: Ukazatel`k soderžaniju, 1756$1760\left[\right.$ Le journal «Sanktpeterburgskie vedomosti » du XVIII ${ }^{-e}$ siècle : Index thématique, 1756 1760], SPb., 1994. 
Laval, à la même époque, on n'enseignait que le français, l'histoire, la géographie et l'arithmétique ${ }^{96}$. Chez Carbonnet, on proposait la géométrie, l'écriture, le portrait, le dessin de fleurs, la lecture et l'écriture en russe, la grammaire russe, le clavecin, la danse et, bien entendu, les langues étrangères. Notons aussi les cours de «politesse », où les élèves apprenaient «leurs obligations les uns envers les autres ${ }^{97}$. L'importance accordée aux matières destinées à enseigner les bonnes manières et le comportement en société (la danse, le dessin, le clavecin, les langues...) est à comparer à celle, souvent plus faible, des matières transmettant un savoir (la physique, les mathématiques, etc..$^{98}$ ). L'établissement de Jean-Théophile de Challes, ouvert en 1772, ne déroge pas à la règle : on y enseignait, entre autres, la mythologie, la danse et la musique ${ }^{99}$. Cette dernière matière était souvent présente dans les programmes d'enseignement. Des cours de musique sont dispensés, par exemple chez Mme Girard ${ }^{100}$ (qui avait aussi une classe de danse, son mari étant maître de ballet à Saint-Pétersbourg à la fin des années 1770) et chez Joseph JolyDebromt ${ }^{101}$.

Parallèlement au russe, au français et à l'allemand, qui étaient presque toujours enseignés, l'italien ne faisait que de rares apparitions ; plus rares encore étaient le latin ou l'anglais ${ }^{102}$. La faible représentation du latin doit évidemment être remarquée : cette langue était alors au cœur des collèges classiques en Europe même si progressivement elle se vit évincée par les langues vivantes dont l'utilité pour la vie en société et l'exercice d'un métier était désormais évidente ${ }^{103}$. Le français restait incontournable. En Russie, à l'exception d'un ou deux établissements,

96. SPFA RAN, f. 3 , op. 9, d. $78, f^{\circ} 16$.

97. Ibid., $\mathrm{f}^{\circ} 7$.

98. Une opposition sur laquelle insistent W. Berelowitch et O. Medvedkova, Histoire de SaintPétersbourg, op. cit., p. 208

99. Voir «Avis au public sur un établissement pour l'instruction de la jeunesse, de l'un et de l'autre sexe, approuvé par l'Académie impériale des sciences. Dirigé par le Sieur Jean Théophile de Challes, Saint-Pétersbourg, 1772», cité dans : W. Berelowitch et O. Medvedkova, Histoire de Saint-Pétersbourg, op. cit., p. 208.

100. $S P b V, \mathrm{n}^{\circ} 60,1776$, cité dans P. Stolpjanskij, « Častnye školy... », art. cit., p. 15.

101. P. Stolpjanskij, « Častnye školy... », art. cit., p. 17-19 (SPbV, n 5, $1775 ; \mathrm{n}^{\circ} 10,1776$; $\mathrm{n}^{\circ} 5,1777$, etc.)

102. RGIA, f. 730, op.1, d. 41, f $539-542$.

103. Sur la place du latin dans la tradition éducative européenne et son rôle secondaire dans les établissements éducatifs russes, voir l'article cité de W. Berelowitch et G. Smagina, p. 54, 56. Il nous semble que l'absence du latin dans les pensionnats privés en Russie, outre le fait que la tradition classique, peu connue jusqu'alors en Russie, avait du mal à prendre racine, relève aussi de la logique propre aux pensions. Leurs directeurs prenaient en compte les vœux de leur clientèle. Le latin était nécessaire principalement pour continuer les études à l'université, or les enfants de nobles ou de commerçants russes choisissaient d'autres voies. Ceci dit, il est vrai que, dans les écoles privées, le latin était plus enseigné dans certains pays européens qu'en Russie, même s'il était en perte de vitesse (voir infra l'exemple de la Suède). Les enseignants de latin n'étaient pas aussi rares en Russie qu'on peut le penser : d'après nos calculs approximatifs, sur plusieurs dizaines de précepteurs examinés à l'Académie des sciences en 1757-1758, près d'un quart possédait le latin. Tous avaient l'intention de l'enseigner et quelques-uns l'avaient déjà fait, mais à domicile, non en pension. Voir : SPFA RAN, f. 3, op. 9, d. 78, 80. 
tous l'incluaient dans leur programme. Dans sa lettre adressée à l'Académie des sciences, Saucerotte cite les langues enseignées chez lui, mais c'est seulement pour le français qu'il énumère les aspects sur lesquels porte son enseignement: la prononciation, la grammaire ( « les principes »), le style, mais aussi le « goût » de la langue, sa «pureté », son «génie », etc. Il va jusqu’à citer les professions pour lesquelles la connaissance du français écrit et parlé est indispensable $\mathrm{e}^{104}$.

On trouve également des matières comme l'escrime, qui nécessitent le paiement d'un supplément (pension de Champagnolot à Moscou en 1768)105 ou bien encore, chez De Challes, l'artillerie, la fortification et la physique, assez rares ${ }^{106}$. Ce dernier pensionnat s'adresse à une clientèle noble, dont les enfants étaient destinés en priorité au service militaire ; De Challes lui-même a été militaire avant de devenir éducateur. On retrouve ces matières chez quelqu'un comme Vojtehovskij*, à Moscou, qui n'enseigne pas les langues mais l'artillerie, le nivellement, etc., disciplines bien connues de cet ancien militaire (le maître reçoit les félicitations des inspecteurs $)^{107}$. Sur les 48 élèves sortis de son pensionnat avant 1785, 25 deviendront militaires. Jean Masson, ancien enseigne (praporščik), professeur de français au Corps des cadets du génie et de l'artillerie, tient un pensionnat où il accueille comme externes quatre élèves de ce Corps ${ }^{108}$. On peut donc sans doute parler de l'apparition d'écoles privées à dominante militaire à l'époque de Catherine II, phénomène tout à fait nouveau pour la Russie.

Mais ce genre d'écoles semi-professionnelles était néanmoins très rare. On peut en citer un cas à Moscou. Louis Méart, Français, peintre de son métier, y tient un pensionnat ordinaire vers 1792 et décide un jour d'ouvrir une école de dessin. Il veut attirer surtout la noblesse qui « tende à la perfection des beaux arts », alors que l'Académie des beaux-arts de Saint-Pétersbourg est bien trop loin.

Cette école sera ouverte trois fois la semaine l'après midi entière et ses exercices dureront deux heures, depuis trois jusqu'à cinq. [...] Pour un sujet qu'on voudroit donner à demeure pendant l'année entière, pour profiter de la leçon de chaque jour; y être logé, nourri, chauffé et éclairé, le billet de souscription sera de cent roubles, et l'on fera un contract. [...] La souscription sera ouverte dès ce jour, jusqu'à-ce que le nombre proposé de soixante souscripteurs soit rempli. $[\ldots]^{109}$.

104. SPFA RAN, f. 3, op. 9, d. 78 (1757), f ${ }^{\circ}$ 3. Le texte complet de cette lettre est placé en annexe $\left(\mathrm{n}^{\circ} 1\right)$.

105. $M V, 1768, \mathrm{n}^{\circ} 13,22,23$.

106. W. Berelowitch, O. Medvedkova, Histoire de Saint-Pétersbourg, op. cit., p. 207-208.

107. K. V. Sivkov, « Častnye pansiony... », art. cit.

108. RGIA, f. 730, op. 1, d. 70, f $39-39 v^{\circ}$; SPFA RAN, f. 1, op. 2 (1780), d. 4, f 24-25. Nous remercions Mme Galina Smagina qui nous a aimablement communiqué cette information.

109. CIAM, f. 16, op. 1, d. 390. Je remercie Julie Ollivier-Chakhnovskaïa qui m'a aimablement communiqué ces informations. 
La comparaison avec la Suède nous permet de constater que les matières enseignées étaient à peu de choses près les mêmes : on trouve les langues étrangères, et avant tout le français, l'histoire, la géographie et les mathématiques. Mais dans les pensionnats suédois on enseigne aussi la correspondance d'affaires et le latin ${ }^{110}$, pratiquement ignoré en Russie dans les écoles privées de la deuxième moitié du XVIII ${ }^{\mathrm{e}}$ siècle.

Qu'en est-il de la qualité de l'enseignement? Les rapports des commissions ne sont pas très flatteurs, les pensionnats français en particulier sont sévèrement critiqués. Ainsi, un nommé Linque (?), qui donne des cours de français dans sa pension, reconnaît n'avoir pas une connaissance approfondie de la grammaire française et, pour cette raison, s'en remettre à la seule dictée d'extraits de Pierre Restaut, auteur populaire de grammaires ${ }^{111}$. La description de l'établissement de Jean Masson ne manque pas non plus de piquant :

Son enseignement de l'histoire est inutile aux élèves et ne correspond pas à son objet. À la question de savoir quelle méthode il utilisait en histoire, sa réponse fut : il commence par l'Histoire Sainte de Hübner. À la question réitérée de savoir comment il enseigne l'histoire à ses Elèves de 15 ans, il répondit : par les Quatre Monarchies. Lorsqu'on lui demanda de donner un exemple de son enseignement de l'histoire d'un peuple et de son ordre social, il choisit lui-même la monarchie assyrienne et nomma les principaux personnages de l'histoire de cette monarchie [...]. N'explique-t-on rien d'autre aux élèves que ces personnages ? Rien sur la situation intérieure et extérieure, ni sur le gouvernement et les mœurs du peuple, etc. ? Ces questions ont étonné M. Masson.

La géographie est enseignée chez Masson à peu près de la même façon : on cite essentiellement le nom des pays, des fleuves et des villes, mais on ne dit mot sur le commerce, l'artisanat ou les ressources naturelles des pays étudiés. On n'utilise pas le globe terrestre. En somme, l'enseignement de ces deux matières n'était pas bien conçu. Les mathématiques étaient mieux enseignées car Masson faisait appel à des professeurs du Corps du génie et de l'artillerie, qui avaient une certaine expérience de l'enseignement et des connaissances suffisantes dans cette matière. Pour le russe, il faisait appel au Français Guilert, né en Russie, qui exerçait aussi dans d'autres pensionnats et dont on louait généralement l'enseignement. Avec l'allemand, la situation était moins brillante : les enseignants le maîtrisaient assez mal. C'est Masson qui enseignait le français, assisté d'un gouverneur. Si la commission loua son enseignement, elle déplora l'absence de division des élèves en classes : ils apprenaient tous ensemble, quel que fût leur niveau ${ }^{112}$. Un autre pensionnat fut

110. E. Hammar, « La Française » : mille et une façons d'apprendre le français en Suède avant 1807, op. cit., p. 37.

111. Ces informations proviennent des dossiers suivants : SPFA RAN, f. 1, op. 2, d. 4 (1780), $\mathrm{f}^{\circ}$ 6-7 (nous remercions Mme Galina Smagina pour cette information) ; RGIA, f. 730, op. 1, d. $30, \mathrm{f}^{\circ} 38$.

112. Trad. du russe. RGIA, f. 730, op. 1, d. 70, f $39-39 \mathrm{v}^{\circ}$; SPFA RAN, f. 1, op. 2, d. 4 (1780), $\mathrm{f}^{\circ}$ 24-25 (nous remercions Mme Galina Smagina de nous avoir communiqué les informations issues de ce dossier d'archives); $S P b V, \mathrm{n}^{\circ} 103,1778$. 
critiqué, celui de Jean-Louis Aullery (?). Ce dernier était pourtant diplômé de l'université de Strasbourg (comme Masson) et n'était pas novice dans la profession : son établissement fonctionna de 1770 à 1788. La commission qui l'inspecta en 1784 trouva son enseignement de l'histoire et de la géographie « tout à fait étrange ». Il n'y avait pas de cours magistral, chaque élève étudiait individuellement avec le professeur. Aullery abusait de dictées. Il maîtrisait parfaitement le français, mais son allemand était boiteux et son enseignement en souffrait ${ }^{113}$.

Ce qui distinguait les pensionnats français des établissements allemands était donc moins l'éventail des matières enseignées que la qualité de l'enseignement. Les matières du cycle général comme l'arithmétique, la géographie et l'histoire n'étaient pas les points forts des établissements français. Mais le français y était mieux enseigné, et à cet égard leur réputation se maintint tout au long du siècle.

L'apprentissage du français s'organisait à cette époque de la façon suivante : d'abord la lecture et l'écriture, puis les «principes », c'est-à-dire la grammaire, et enfin le «style », plus difficile, que l'on enseignait plus rarement. Il s'agit d'une méthode classique qui était à la base de la plupart des « manuels ». Ainsi, les élèves de Jean Masson passaient par la lecture et l'écriture, puis par la grammaire. On leur donnait ensuite des exercices de traduction et on leur «montrait le style ${ }^{114}$. De même chez l'Allemand Baman : « dès que les élèves ont appris à lire avec le professeur nommé Mourois, [M. Baman - V.R.] leur donne à traduire des expressions. Il a même déclaré aller jusqu'à leur enseigner le style »115. Voici, par exemple, comment on apprenait à lire (à Saint-Pétersbourg en 1784) au pensionnat de Iohann Herman Knirim : «Il écrit au tableau en lettres capitales des sentences morales ou plus légères et amusantes en russe, allemand et français, ainsi que des syllabes séparées, les enfants les assemblent et les lisent ensemble jusqu'à ce qu'ils puissent lire facilement et presque par cœur ${ }^{116}$. Les Allemands utilisaient surtout la méthode « grammaire/traduction ». Dans la pension de Johann Friedrich Pizker, les enfants apprenaient d'abord à lire et écrire, ensuite ils attaquaient la grammaire Des Pepliers, et enfin, apprenaient à traduire du français vers le russe. Ceci étant, la commission remarqua que le maître de pension, originaire de Prusse, n'était pas vraiment qualifié pour enseigner le français et qu' «il devait trouver un bon professeur $»^{117}$.

Il convient de préciser qu'à l'origine en Russie l'enseignement du français se faisait en allemand car les premiers enseignants de français étaient souvent germanophones. La vocation universelle du français y était évidemment pour quelque chose, mais surtout le fait que beaucoup de professeurs allemands venaient de milieux lettrés, étaient souvent diplômés des universités, et avaient été en contact

113. RGIA, f. 730 , op. 1 , d. $70, \mathrm{f}^{\circ} 45 \mathrm{v}^{\circ}$; op. 2 , d. $49, \mathrm{f}^{\circ} 1-4 \mathrm{v}^{\circ}$.

114. RGIA, f. 730, op. 1, d. 70, f $39-39 \mathrm{v}^{\circ}$; SPFA RAN, f. 1, op. 2, d. 4 (1780), f $24-25$ (je remercie Mme Galina Smagina pour cette information); $S P b V, \mathrm{n}^{\circ} 103,1778$.

115. Trad. du russe. RGIA, f. 730 , op. 1 , d. $70, f^{\circ} 36$.

116. Ibid., $\mathrm{f}^{\circ} 41$.

117. Ibid., f ${ }^{\circ} 38$. À ce sujet, voir les travaux de K. Koh. 
avec la langue française dans cette Europe où le français était largement utilisé. L'exercice de la traduction, particulièrement goûté, se faisait donc moins rarement du français vers le russe que vers l'allemand (par ex. dans les pensions d'Andreï Davison et de Johann Georg Vedemeyer; ce dernier utilisait des livres traduits de l'une ou l'autre langue) ${ }^{118}$. Les maîtres français se pliaient parfois aussi à cette règle : chez Carbonnet, la Bible était lue et traduite en français et en allemand. Mais, le plus souvent, les Français employaient une sorte de méthode directe avant l'heure et enseignaient le français en français, connaissant mal d'autres langues. Les inspecteurs le disent sans détours : ainsi, Amiette, «Français d'origine » travaillant chez Ernst Flitcher, « parle bien et peut enseigner, mais a des faiblesses en traduction, ne connaissant pas suffisamment les langues autres que la sienne $»^{119}$.

La littérature destinée à l'apprentissage de l'allemand en Russie a déjà fait l'objet d'étude ${ }^{120}$. En revanche, on connaît moins bien les manuels d'enseignement du français ${ }^{121}$. Dans les années 1730 les premiers «manuels » de français destinés spécialement aux apprenants russes font leur apparition. Cette production s'étoffe seulement à partir des années 1760, accusant un retard considérable de la Russie par rapport à l'Europe de l'Ouest et du Nord où les grammaires françaises à l'usage des autochtones étaient éditées dès le XVII ${ }^{\text {e }}$ siècle. Les grammaires connues (Restaut, de la Touche, Des Pepliers...), souvent en provenance des territoires allemands, étaient aussi traduites en Russie. Les auteurs des grammaires « originales » pour les russophones éditées en Russie sont souvent russes : Vasilij Bunin, Martyn Sokolovskij, Vasilij Protopopov, Ivan Astahov..., mais quelques-uns sont des étrangers dont la présence sur le sol russe est attestée : Delaval, G. Gautier, J.-F. Fabian, l'abbé Moisan ou encore ce Boudri, frère du révolutionnaire Marat, qui renonça, à cause de celui-ci, à son patronyme ${ }^{122}$. La plupart de ces grammaires sont évidemment des compilations ou des adaptations de manuels connus. Même si les grammaires représentaient le support le plus répandu pour l'apprentissage du français, on trouvait également d'autres ouvrages, des «Guides» (F. Karžavin), des « Conversations » (Fabian), etc. L'un des auteurs les plus prolifiques du début du XIX', Théodore-Jean Courtener, descendant d'un émigré français, signera plusieurs «manuels » dont certains se présentent comme des livres de lecture.

Mais toute cette littérature était apparemment peu utilisée dans les pensionnats. Les outils pour l'apprentissage du français y étaient, en général, les mêmes que dans le reste de l'Europe, si bien qu'on peut parler, avec quelques réserves, d'un espace paneuropéen dans ce domaine. On étudiait surtout d'après les livres de

118. Ibid., $\mathrm{f}^{\circ} 44 \mathrm{v}^{\circ}$.

119. Ibid., $\mathrm{f}^{\circ} 47 \mathrm{v}^{\circ}$. Trad. du russe.

120. Voir avant tout K. Koh, «Prepodovanie nemeckogo jazyka...», op. cit., p. 38-41, et les travaux de Galina Smagina.

121. Une des premières approches de cette question est faite par Wladimir Berelowitch avec lequel nous entendons mener une enquête sur les « manuels » utilisés en Russie à cette époque et plus précisément ceux qui étaient utilisés dans l'apprentissage du français. Voir : W. Berelowitch, G. Smagina, « Enseignants et modèles éducatifs français... », op. cit., p. 61-63.

122. Pour les références de ces livres, le lecteur est prié de se reporter à l'annexe $n^{\circ} 8$. 
Restaut, de Des Pepliers, la Grammaire des dames, le Magasin des enfans de Mme Leprince de Beaumont et Télémaque ${ }^{123}$, déjà cités. On utilisait aussi, on l'a vu, la Bible dont la traduction en différentes langues était disponible.

Il est important de noter que les matières générales étaient souvent enseignées dans une langue étrangère parce que les professeurs maîtrisaient mal le russe. Il est difficile de mesurer à quel point les élèves pouvaient bénéficier d'un tel enseignement car ceux-ci formaient un groupe très hétérogène : à côté d'enfants d'origine française, on trouvait des enfants d'autres origines notamment des Russes, qui n'avaient probablement pour tout bagage que les leçons particulières d'un précepteur. Il est évident que les enfants ne comprenaient pas toujours les professeurs. Lorsque Andrej Bolotov évoque ses années d'étude au pensionnat de Daniel Féray, il compare sans le vouloir cet établissement avec ceux de l'époque de Catherine II en s'exclamant : « Ceci [il s'agit ici du fait que l'histoire et la géographie n'étaient pas enseignées chez les Féray - V.R.] est peut-être mieux que d'enseigner comme on le fait aujourd'hui [en 1789 - V.R.] dans les pensionnats où on ne fait que perdre son temps et il n'en ressort aucune utilité, car on oblige les enfants à apprendre ces deux sciences [la géographie et l'histoire, donc - V.R.] par cœur en français, alors qu'ils n'y comprennent rien ».

« Il s'est présenté à l'Académie des sciences pour l'examen, annonçant pour lui-même qu'il était français d'origine »

Extrait d'une attestation délivrée par l'Académie des sciences à un maître de pension.

«Il pourrait être forcé de continuer encore ce métier » Extrait d'une lettre d'un gouverneur à l'Académie des sciences ${ }^{124}$.

Qui étaient ces maîtres de pension et ces enseignants ? Y avait-il parmi eux des pédagogues de métier? Quel était leur bagage culturel ?

La grande majorité des maîtres de pension étaient des étrangers. Il n'est pas toujours aisé d'établir leur origine, mais des calculs estimatifs permettent d'affirmer qu'à Saint-Pétersbourg, un tiers des maîtres de pension était français, la majorité était manifestement germanophone, originaire des territoires allemands, de Finlande, de Livonie et parfois nés à Saint-Pétersbourg. Il n'y avait pratiquement pas d'Anglais, à l'exception de Mme Cock (ou Cack), et peu de Suisses. Moscou, semble-t-il, comptait plus de Français parmi les maîtres de pension, mais les données disponibles sont incomplètes. Parmi les professeurs, outre les Français et les «Allemands», on comptait plusieurs Russes. Ces derniers enseignaient le russe, les Écritures, mais aussi d'autres matières, généralement l'arithmétique et la géométrie ${ }^{125}$.

Une partie des pensionnats étaient des écoles paroissiales. Il s'agit essentiellement de paroisses protestantes. Les maîtres de ces pensionnats étaient pour la

123. Voir l'annexe $n^{\circ} 9$.

124. PFA RAN, f. 3 , op. 9 , d. $78, f^{\circ} 2,8$.

125. Certains enseignaient l'histoire, le dessin et même la danse, matière qui était habituellement la spécialité des Français. 
plupart des pasteurs. Par exemple, l'école d'un certain Heinrich Wilhelm Walter fut fondée à la demande de l'église finnoise et avec l'autorisation du collège de Justice ; on pourrait citer également les pensionnats des pasteurs Colbe (?) et Friedrich Renibolt ${ }^{126}$. En règle générale, ces pasteurs étaient allemands et leurs écoles dépendaient sans doute d'une paroisse, mais officiellement les autorités russes ne leur accordaient aucun statut particulier.

Nous l'avons vu, il n'y eut pendant longtemps aucun contrôle réel de l'activité des pensionnats, ce qui revient à dire que n'importe qui pouvait ouvrir une école privée. C'est une des raisons pour lesquelles on trouve peu de pédagogues de profession parmi les maîtres de pension, mais beaucoup d'étrangers de passage, à la recherche d'une source de revenus. Voici quelques cas qui nous semblent caractéristiques.

Le Français Dubof tenait un pensionnat à Moscou en 1785. Il avait un document de l'église catholique attestant de son comportement irréprochable. On peut penser qu'il s'agit de Jean Dubof (ou Du/De Bof), connu comme recruteur de colons pour la Russie sous Catherine II, camarade des recruteurs et aventuriers Meunier de Précourt et d'Hauterive. Né vers 1734 en Picardie, il se disait ingénieur-géographe. Il vint en Russie en 1764 afin de diriger la colonie Franzosen-Rossoschi, sur la Volga. Comme ses administrés, il passa une dizaine d'années au bord de la Volga avant de s'installer à Moscou' ${ }^{127}$. S'il s'agit bien de la même personne, Dubof était maître en beaucoup de choses, mais n'avait jamais eu l'occasion d'enseigner auparavant. Il avait ouvert son pensionnat sans obtenir l'autorisation de l'Université. La commission émit un avis très critique sur ses compétences : «les enfants apprennent le français, l'allemand, l'histoire, la géographie, la grammaire russe, mais avec de piètres résultats, l'arithmétique avec des résultats moyens, ils n'apprennent pas la Loi Divine et leur éducation laisse beaucoup à désirer ${ }^{128}$. Le maître de pension prenait 150 à 180 roubles par élève. La Commission décida que l'établissement devrait être fermé.

François-Eloi Saucerotte n'était pas plus familier du métier de pédagogue. Il était acteur, né à Raucourt en France, et utilisa le nom de sa ville natale comme nom de scène. Raucourt débuta à la Comédie française à Paris sans en être membre permanent. À la fin des années 1740, il tenait les premiers rôles dans la troupe de De Sérigny à Saint-Pétersbourg et, lorsque la troupe fut dissoute, se lança dans l'enseignement, domaine fort lucratif. Il tenait une pension et enseignait aussi à domicile : en 1757, il vivait chez le comte Aleksej Grigor'evič Razumovskij, feld-maréchal, favori de l'impératrice Élisabeth, en qualité de précepteur des enfants ${ }^{129}$. Le Fran-

126. Voir la liste des maîtres de pension en annexe ( $n^{\circ} 6$ et 7$)$.

127. V. Ržeuckij, « Les Français de la Volga : la politique migratoire russe des années 1760 et la formation des communautés francophones à Saint-Pétersbourg et à Moscou », Cahiers du Monde russe, 39 (3), 1998, p. 283-296.

128. K. V. Sivkov, « Častnye pansiony... », art. cit.

129. P. Corvin, Le théâtre en Russie depuis ses origines jusqu'à nos jours, Paris, 1890, p. 8089, 172 ; P. Stolpjanskij, « Častnye školy... », art. cit., p. 17-18; R.-A. Mooser, Contribution à l'histoire de la musique russe : L'Opéra-comique français en Russie au XVIII' siècle, Genève, 1954 , p. 23. 
çais Jean Linque qui, on l'a vu, connaissait mal la grammaire française, maniait l'épée bien mieux que la plume car il avait été à ses débuts maître d'escrime au Corps des cadets du génie ${ }^{130}$. Michel Spark (?), un huguenot tenant une pension à Saint-Pétersbourg en 1757, était également chanteur à l'église luthérienne ${ }^{131}$. Johan Tobitch (?) était coiffeur, mais il ne pouvait subvenir aux besoins de sa famille qu'en «enseignant à l'école »132. Il y avait encore plus de militaires (souvent des déserteurs) qui se lançaient dans l'enseignement (rappelons le cas de De Challes et de Vojtehovskij*).

Dans de nombreuses écoles l'enseignement manquait donc cruellement de professionnalisme. Les descriptions laissées par les inspecteurs sont révélatrices: « Christophe Ergard est à l'évidence le plus ignorant et le plus incompétent de tous les maîtres de pension »; «G. Binkenet* n'enseigne en français que la lecture et l'écriture, ne montrant aucune règle de grammaire [...] il lit bien, étant français d'origine, mais ne connaît aucune règle »; dans l'établissement de Friedrich Wilhelm Reinekin (?), le professeur de français « n'est aucunement en état d'enseigner cette langue »; chez Jean Linque, le professeur d'arithmétique, Bojken*, «n'a ni manuel ni méthode et ses connaissances sont parfaitement insuffisantes dans ce domaine »; Ludwig Schumacher enseignait lui-même le russe dans son école «bien qu'il ne connaisse pas bien l'alphabet »; Vasilij Turgenev, l'unique maître de pension russe ayant réussi à s'immiscer parmi les étrangers à Saint-Pétersbourg dans les années 1780, se vit aussi critiquer de façon humiliante : « il lit et écrit mal l'allemand et ne devrait pas l'enseigner. Il ne connaît pas non plus les règles d'écriture en russe », etc. ${ }^{133}$

Cependant, il faut nuancer l'opinion, largement répandue, selon laquelle les gouverneurs et les maîtres de pension possédaient un niveau culturel désespérément bas. Les Français souffraient certes de la comparaison avec leurs collègues allemands ${ }^{134}$, mais il y avait d'assez fréquentes exceptions à la règle.

Parmi les maîtres de pension de Saint-Pétersbourg, nous trouvons un certain Ivan Gillet, enseignant à l'Académie des beaux-arts. Il s'agit sans doute de NicolasFrançois Gillet, étant donné qu'on ne connaît pas d'autres Gillet dans cette institution à la même époque. Gillet arriva en Russie en 1758 et commença dès lors à enseigner la sculpture à l'Académie, dont il sera un temps directeur ${ }^{135}$.

Le Français de Laval (déjà mentionné, il tenait un pensionnat vers 1752) est sans doute auteur d'une grammaire française publiée à Saint-Pétersbourg en 1752. Cette

130. RGIA, f. 730 , op. 1 , d. $70, \mathrm{f}^{\circ} 38 \mathrm{v}^{\circ}$.

131. SPFA RAN, f. 3 , op. 9 , d. $78, f^{\circ} 36$

132. RGIA, f. 730 , op. 1, d. $70, \mathrm{f}^{\circ} 47 \mathrm{v}^{\circ}$. Trad. du russe.

133. RGIA, f. 730, op. 1, d. 70. Trad. du russe.

134. SPFA RAN, f. 3, op. 9. Ce seul dossier suffit pour s'en convaincre : parmi les gouverneurs et maîtres de pension allemands, on trouve régulièrement des diplômés d'université.

135. E. B. Mozgovaja, «Professor skul'pturnogo klassa Sankt-Peterburgskoj Akademii hudožestv Nikola Fransua Žille» [Nicolas-François Gillet, professeur de sculpture à l'Académie des beaux-arts de Saint-Pétersbourg], in XVIII vek kak istoriko-kul'turnyj fenomen : Problemy izučenija [Le XVIII siècle en tant que phénomène historique et culturel : Problèmes d'étude], sb. nauč. statej pod red. E .B. Mozgovoj, SPb., 2002, p. 29-34. 
grammaire touffue est dédiée au prince Jurij Nikitič Trubeckoj (1736-1811, futur conseiller d'État actuel, fils du procureur général, futur feld-maréchal Nikita Jur'evič Trubeckoj) chez lequel de Laval se trouvait en qualité de précepteur ${ }^{136}$.

À Moscou, plusieurs enseignants de l'université ou de la pension noble auprès de l'université tenaient des pensionnats éducatifs. Jean-Jacques-Etienne Baudoin, natif de Rouen, entra à la faculté en 1776, remplaçant Berland de la Bordelière qui venait de décéder. Cette même année, il reçut l'attestation de l'université et les commentaires des examinateurs furent enthousiastes : le candidat maîtrisait parfaitement le français, possédait très bien sa grammaire, était expert en latin, pouvait traduire et commenter les auteurs latins, avait de solides connaissances en histoire et en géographie. « En un mot, écrivait l'examinateur, parmi les Français qui se présentent ici, on trouvera rarement quelqu'un qui ait les mêmes connaissances »137. À l'université, Baudoin donnait des cours d'étymologie, de stylistique et de traduction française. Il enseigna jusqu'à sa mort en 1796. Il prononça de nombreux discours à l'occasion de célébrations à l'université et laissa un recueil de poésie. Certains de ses écrits furent publiés ${ }^{138}$. À partir de 1777 , il tint un pensionnat privé, situé chez le prince Pëtr Ivanovič Odoevskij, entre les rues Arbat et Povarskaïa. Dans son école, les enfants apprenaient « la conversation, la traduction et la rédaction de lettres ». Le français, l'allemand et le latin étaient enseignés par Baudoin lui-même «selon les règles ». Les exercices pratiques cherchaient à développer surtout la conversation, la traduction et la rédaction. Le maître de pension employait manifestement la méthode classique « grammaire/traduction ${ }^{139}$. Baudoin était en outre syndic à la paroisse de l'église catholique des Saints-Apôtres-Pierre-et Paul. On connaît d'autres exemples de ce genre (comme le chevalier Michel de Leroux).

$\mathrm{Au}$ début du XIXe siècle, un autre enseignant à l'université, Charles Aviat de Vatay, aidé d'un collègue, Jean-Baptiste Maudru du Bocage, ouvrit (ou s'apprêtait à ouvrir ?) un pensionnat. Ces deux personnalités sont dignes d'intérêt. Aviat de Vatay avait succédé à Baudoin à l'université où il enseignait la rhétorique, la littérature française, la traduction d'auteurs russes en français (lui-même traduisit l'ode de Deržavin Bog (Dieu)). En 1799, Aviat de Vatay édita sa traduction de Kamin (La cheminée), une œuvre du prince Ivan Mihajlovič Dolgorukij ${ }^{140}$, il fit aussi des

136. Pour la référence, voir l'annexe $n^{\circ} 8$.

137. En français dans le texte. PFA RAN, f. 3, op. 9, d. 239 (1773), $\mathrm{f}^{\circ} 15$.

138. Voir : Svodnyj katalog knig na inostrannyh jazykah, izdannyh v Rossii v XVIII veke, 1701-1800 [Catalogue collectif des ouvrages en langue étrangères publiés en Russie au XVIII S., 1701-1800], 3 vol., L.: Nauka, 1984-1986, t. 1, p. 83. Sur Baudoin, voir: Biografičeskij slovar' professorov i prepodavatelej Moskovskogo universiteta za istekajuščee stoletie, so dnja učreždenija 120 go janvarja 1755 po den'stoletnego jubileja janvarja 12 ogo 1855 goda [Dictionnaire biographique des professeurs et enseignants de l'université de Moscou des 100 dernières années, depuis le jour de sa fondation, le 12 janvier 1755, jusqu'au jour de son centenaire, le 12 janvier 1855], t. 1-2, Moscou, 1855, t. 1, p. 92.

139. $M V, 1777, \mathrm{n}^{\circ} 2$.

140. Kamin, sočinenie knjazja I. Dolgorukova, M., 1801 (il existe apparemment aussi une édition de 1799). D'autres traductions du russe d'Aviat de Vatay sont connues. Voir: V. S Sopikov, Opyt rossijskoj bibliografii [Essai de bibliographie russe], SPb., 1904, n 5013, 6918. 
traductions restées inédites des œuvres de Ippolit Fëdorovič Bogdanovič. Maudru se trouvait au service du Corps des cadets nobles de l'armée de terre à Saint-Pétersbourg dès 1771. Professeur de français, il mena également une carrière scientifique : il édita des manuels où il expliquait sa méthode d'apprentissage de la lecture ; il fit partie, avec Pierre-Charles Levesque, futur historien de la Russie, du cercle d'intellectuels qui se réunissaient chez Johann Albrecht Euler, membre de l'Académie des sciences de Saint-Pétersbourg. En 1775, il était maître de pension dans la capitale. Par la suite, dans les années 1790, il fut soupçonné de sympathies pour les révolutionnaires français. Selon ses dires, après quelques mois de détention, on l'expulsa de l'empire russe. Mais en France, le sort ne lui fut pas plus clément : en quelque sorte exclu de la vie scientifique, il fut contraint, au début du siècle suivant, de retourner en Russie où il eut la chance de pouvoir s'établir à nouveau. Au moment du projet de pension élaboré avec Aviat de Vatay, il était déjà un philologue chevronné, auteur d'une grammaire russe ${ }^{141}$.

D'autres enseignants français à l'université de Moscou tenaient également un pensionnat, par exemple Abraham-Auguste-Louis Wille, «maître d'Art » ${ }^{142}$, et Jean-Godfroy de Saint-Nicolas qui tenta même de faire passer l'examen de l'université aux élèves de son pensionnat, ce qui lui fut refusé. Les Français n'étaient pas seuls à ouvrir des pensionnats. Čebotarev, professeur russe, et Chaden (?), hongrois ayant enseigné à Tübingen, étaient tous deux professeurs à l'université de Moscou et tenaient des pensionnats dans cette ville dans les années 1780 (N. M. Karamzin, célèbre historien, fut élève dans l'établissement de Chaden) ${ }^{143}$.

On pourrait citer d'autres maîtres de pension dont la carrière prouve la compétence dans cette profession. C'est le cas de Jacques de Villeneuve (ou Villeneuf). Peu de temps après son arrivée à Saint-Pétersbourg en 1751, Villeneuve obtint une place chez le compte Šeremetev, certainement P. B. Šeremetev, général en chef et sénateur, l'un des hommes les plus riches de son temps. Après trois ans chez les Šeremetev, Villeneuve se rendit à Stockholm où il aurait été précepteur dans la

141. Éléments raisonnés de la langue russe, ou principes généraux de la grammaire appliqués à la langue russe, par Jean-Baptiste Maudru, Paris, chez l'auteur, an X (1802), 2 vol., in-8 $8^{\circ}$. Voir sur lui : S. Archaimbault, « Jean-Baptiste Maudru ou le regard de la Grammaire générale française sur la langue russe », Slavica Occitania, n 6, 1998, p. 13-26 ; Biografičeskij slovar professorov i prepodavatelej Moskovskogo universiteta..., op. cit, t. 1, p. 150-151; Catalogue général des livres imprimés de la Bibliothèque nationale, Auteurs, t. 110, col.89-91 ; G. Dulac, «La vie académique à Saint-Pétersbourg vers 1770. D'après la correspondance entre J. A. Euler et Formey », Académies et sociétés savantes en Europe (1650-1800). Textes réunis par Daniel-Odon Hurel et Gérard Laudun, Paris : Champion, 2000 ; P. Stolpjanskij, « Častnye školy... », art. cit., p. 9, 14, 16, 29. Je remercie Dmitri Gouzévitch pour son aide.

142. L'annonce de ce pensionnat passa dans le journal $M V, 27.10 .1792 ; 3.11 .1792$. Wille avait d'une certaine façon hérité de l'établissement de son épouse qui l'avait tenu avec son premier mari, un certain Parat.

143. Opisanie del arhiva..., op. cit., t. 1, p. 17. Sur Chaden et son pensionnat, voir: Biografičeskij slovar' professorov i prepodavatelej..., op. cit, t. 2, p. 558-574 ; A. P. Stepanov, « Iz istorii vospitanija v Rossii konca prošlogo veka » [De l'histoire de l'éducation en Russie à la fin du siècle dernier], Russkaja škola, n 1, 1891, p. 9-27 ; D. A. Tolstoj (comte), Gorodskie učilišča v carstvovanie imperatricy Ekateriny vtoroj, op. cit., p. 6. 
famille royale. On sait avec certitude qu'il y tint un pensionnat très réputé144. Cette réputation parvint sans doute jusqu'à Danzig, puisque la ville lui offrit un poste de directeur d'école. Villeneuve refusa car il avait déjà accepté d'être gouverneur dans la famille d'un feld-maréchal russe. En 1772 il ouvrit un pensionnat privé sur l'île Vassilievski, où ses propres enfants furent scolarisés. Le pensionnat fonctionna assez longtemps, mais avec le temps son activité déclina : Villeneuve avait près de 20 élèves en 1780, mais trois seulement en 1784. Son établissement était encore en activité en $1788^{145}$. On rencontre aussi des professeurs expérimentés parmi les maîtres de pension d'autres origines, entre autres Johann Georg Vedemeyer qui, avant d'ouvrir son école, enseigna au Corps des cadets nobles de l'armée de terre, et l'Anglaise Mme Cock, gouvernante chez les Razumovskij et enseignante à l'Institut des jeunes filles nobles et à l'école Saint-Pierre ${ }^{146}$.

Le fait de travailler dans un établissement d'éducation relevant de l'État ne garantissait pas la qualité de l'enseignement. Johann Heinrich Baman, avant d'ouvrir son pensionnat, enseigna à l'école Saint-Pierre et au Corps des cadets nobles de l'armée de terre. Cependant, lorsqu'il dut passer son examen à l'Académie des sciences en 1779, il s'avéra qu'il « connaissait l'allemand, mais pas selon les règles grammaticales, et qu'il ne pouvait pas l'enseigner à d'autres. Il parle, écrit et prononce le français comme une langue qui lui est étrangère et qu'il aurait apprise pour son propre commerce et que toute sa connaissance de cette langue ne peut lui être utile que pour cet usage car il n'est pas en état de l'enseigner ${ }^{147}$. La commission ne fut pas impressionnée par les connaissances de Louis Pontet, enseignant au Corps des cadets, qui tenait un pensionnat (ou s'apprêtait à en ouvrir un) $)^{148}$.

L'université n'était pas garante non plus des bonnes mœurs de son personnel. Champagnolot, Français né en Bourgogne en 1736, habitait Moscou dès le début des années 1760. En 1766, il fut reçu à l'examen pour être professeur et travailla comme précepteur chez le général-major de la Garde Mihail Izmajlov ${ }^{149}$. Champagnolot tenait aussi, nous l'avons vu, un pensionnat. Le 3 avril 1767, il entra comme professeur de français au gymnase de l'université dont il fut renvoyé pour incompétence ${ }^{150}$. Après le décès, en 1770 , d'Henri Lavie, lecteur de français à l'université de Moscou, Champagnolot se porta candidat pour occuper son poste. Il avait deux

144. «Le meilleur en son genre, aussi bien en connaissances qu'en mœurs, qui soit jamais venu dans notre pays ». Cité de : E. Hammar, « La Française » : mille et une façons d'apprendre le français en Suède avant 1807, op. cit., p. 49.

145. RGIA, f. 730 , op. 1, d. 70 ; op. 2, d. 49, f $1-4 v^{\circ}$, SPFA RAN, f. 1, op. 2 , d. 4 (1780), f 27 $\mathrm{v}^{\circ}-29$ (je suis reconnaissant à Mme Galina Smagina pour ces informations).

146. RGIA, f. 730 , op. 1, d. $70, f^{\circ} 47 \mathrm{v}^{\circ}$.

147. Ibid., $\mathrm{f}^{\circ} 21$. Trad. du russe.

148. Voir les remarques de la commission en annexe $\left(n^{\circ} 2\right)$.

149. Dokumenty i materialy po istorii Moskovskogo universiteta..., op. cit., t. 2, p. 231-232.

150. RGADA, f. 278 , kn. 6054, f ${ }^{\circ} 9$. Voir aussi Dokumenty i materialy po istorii Moskovskogo universiteta..., op. cit., t. 3 , p. 143. 
concurrents : le Français Pierre-Antoine-Etienne Fauvel et le traducteur et écrivain russe Fëdor Karžavin, diplômé de la Sorbonne. Ce fut ce dernier qui remporta le concours ${ }^{151}$. Il s'avéra que Champagnolot n'était pas en règle avec la loi. En 1776, sa femme fut mise sous les verrous car on soupçonnait les époux de fabriquer de la fausse monnaie ${ }^{152}$

Certains étrangers, dépourvus de formation pédagogique, en faisaient l'acquisition « sur le terrain ». C'est le cas de la famille Delesalle, déjà évoquée. En France, les Delesalle sont fermiers et rentiers. Philippe-Auguste Delesalle arrive en Russie avec sa famille en 1765 afin de s'installer dans la région de la Volga. Son projet échoue et la famille reste dans la capitale pour chercher un emploi. Ces fermiers décident de tenter leur chance dans l'éducation. En 1772, deux d'entre eux trouvent une place de gouverneur à l'Académie des beaux-arts grâce à la recommandation de Nicolas-Gabriel Clerc, futur historien de la Russie. En 1779, Philippe-Auguste ouvre son pensionnat privé sur l'île Vassilievski. L'un de ses fils, sa fille Aldegonde et son gendre François-Hippolyte de Forceville y enseignent. Les Delesalle et les Forceville sont nouveaux dans la profession. Louis-Noël de Forceville, frère de François-Hippolyte et peintre de profession, dirige à la même époque un pensionnat à Moscou ${ }^{153}$. Il est marié à une autre fille de Philippe-Auguste Delesalle, Albertine. Dans les années qui suivent, on trouve Albertine et son frère Dimitri au nombre des professeurs de ce pensionnat. En 1794, Gabriel Delesalle, un autre frère d'Albertine, ouvre son établissement à Moscou où son frère Ignace exerce un certain temps. Les Delesalle acquièrent ainsi de l'expérience dans cette profession qui sera leur gagne-pain non seulement au XVIII ${ }^{\mathrm{e}}$ siècle, mais aussi au XIXe. On peut parler de l'apparition en Russie, pour la première fois, d'une dynastie d'enseignants, fait exceptionnel pour l'époque.

«La Russie confie l'éducation de l'élite de sa jeunesse à un pope français (l'Abbé Nicolle). Mettons qu'il soit homme d'excellentes mœurs avec les connaissances les plus étendues, mais connaît-il les intérêts de notre patrie sous ses différents rapports? Leur inculquera-t-il l'amour de celle-ci ?»

Extrait de la correspondance entre I. V. Sabaneev et le prince M. S. Voroncov (1818)

«Ce maudit Français n'a éveillé chez aucun d'entre eux (hormis Benkendorf) la moindre ambition, ni le désir d'être un jour des membres importants et utiles de la société » Extrait d'une lettre du prince M. S. Voroncov à S. N. Marin (1805) ${ }^{154}$

L'un des derniers pensionnats privés fondés par des Français à Saint-Pétersbourg sous le règne de Catherine II est l'établissement privé le plus connu en Russie au

151. Ibid., p. 403.

152. ANF, AE. B-I- $988, f^{\circ} 124-124 \mathrm{v}^{\circ}$

153. RNB, Mss, f. « raznojaz. rukopisi », F-II, 27/1, f 102.

154. Arhiv knjazja Voroncova, t. 39, 1893, p. 461-462 et t. 36, 1890, p. 88. Je remercie D. Gouzévitch de m'avoir indiqué ces sources. 
XVIII' siècle. Le nom de son fondateur, l'abbé Charles-Dominique Nicolle, suscitait au tournant du siècle soit des exclamations enthousiastes, soit des critiques acerbes. L'ouverture de sa pension sur les bords de la Néva est étroitement liée au contexte de l'époque, à savoir la Révolution française qui est à l'origine d'une des plus grandes vagues d'émigration que connut la France, émigration qui comptait avant tout des membres de la noblesse et du clergé. Du fait des distances qui séparaient les deux pays et des différences de confession, le nombre d'émigrants français en Russie en cette fin de siècle est relativement modeste, quant au nombre de religieux, il est insignifiant : dans les années 1790, quelques dizaines en tout traversent la frontière russe, en incluant dans ce chiffre les moines et les moniales qui ont été alors autorisés à trouver refuge sur le territoire de l'empire ${ }^{155}$.

Les religieux, malgré leur petit nombre, exercèrent cependant une influence culturelle non négligeable. Il y avait relativement peu d'églises catholiques à cette époque en Russie et l'unique place de prêtre français y était, en général, déjà occupée. Il ne restait donc qu'à chercher un emploi d'enseignant : ainsi la quasitotalité du clergé français en Russie à cette époque se convertit à l'enseignement.

Avant de quitter la France, l'abbé Nicolle (né en 1758) était préfet d'études au collège Sainte-Barbe à Paris. Il accepte de devenir le précepteur des enfants du comte Marie-Gabriel de Choiseul-Gouffier et voyage en Italie avec la famille de celui-ci, puis passe à Constantinople, où le comte occupe alors le poste d'ambassadeur. En 1793, le comte accepte l'invitation de se réfugier à Saint-Pétersbourg et l'abbé le suit. Le comte reçoit une pension et des terres, il est nommé à des postes de haut rang : on lui confie la présidence de l'Académie des beaux-arts et la direction des Bibliothèques impériales. L'abbé Nicolle profite de cette situation favorable pour réaliser un rêve qu'il caressait depuis longtemps : ouvrir sa propre institution qui réunirait les qualités de l'éducation publique et de l'éducation particulière ${ }^{156}$. L'institut de l'abbé est créé avec une extrême rapidité : dès 1794, Nicolle informe son ami l'abbé Septavaux qu'il se trouve à la tête d'un établissement qui rassemble seulement six élèves payant une forte somme, ce qui permet d'assurer un revenu convenable à un groupe d'émigrés religieux. Rapidement, l'abbé Nicolle compte plusieurs collaborateurs à ses côtés ${ }^{157}$. Le nombre d'émigrés disponibles dépassait les besoins du pensionnat et l'institut devint bientôt un point de passage : après une halte à Saint-Pétersbourg, les prêtres français poursuivaient leur route vers Moscou.

155. Conclusion sur la base d'une vaste étude de l'émigration française au XVIII ${ }^{\mathrm{e}}$ siècle actuellement en cours d'édition au Centre international d'étude du XVIII ${ }^{\text {e }}$ siècle à Ferney-Voltaire (sous la direction d'Anne Mézin et de Vladislav Rjéoutski).

156. Frappaz, abbé, Vie de l'abbé Nicolle, Paris, 1857, p. 21.

157. Parmi eux les abbés Septavaux, ami proche de Nicolle, Surrugues, futur abbé de l'église Saint-Louis à Moscou ainsi que les pères Chenels, Lavoisier et Salandre, l'abbé Macquard, ancien prêtre du collège Sainte-Barbe, Lémery, du collège de Brienne. M.-J. Rouët de Journel, La Compagnie de Jésus en Russie..., Paris : Perrin, 1922, p. 52; E. Haumant, La culture française en Russie..., op. cit, p. 199; Frappaz, Vie de l'abbé Nicolle, op. cit., p. 348. 
Le pensionnat occupait tout une maison sur la Fontanka, non loin du palais du prince Jusupov ${ }^{158}$. Le nombre d'élèves ne cessant d'augmenter, on décida alors de le limiter à $24{ }^{159}$. Il s'agissait des enfants des familles les plus riches et les plus haut placées de Saint-Pétersbourg : les Jusupov, les Orlov, les Galicyn, les Naryškin, les Gagarin, les Men'šikov, les Benkendorf, le fils du duc Louis de Wurtemberg... Le prix des études était très élevé (selon certaines sources, près de 1500 roubles à l'année, une somme énorme pour l'époque), et l'établissement ne manquait pas de moyens matériels. Le succès de cette entreprise tient en partie à la renommée de Choiseul-Gouffier, mais aussi au prestige dont jouissait le clergé français, que l'aristocratie russe plaçait bien au-dessus des autres gouverneurs français, ce qui explique pourquoi les prêtres français trouvaient alors facilement une place d'éducateur dans les maisons de la haute société.

À l'institut, on apprend le français et le latin, la géographie, les mathématiques, «les principes moraux et religieux $» 160$. Pour des raisons évidentes, le latin retrouve ici ses droits. Il n'y a pas que des religieux parmi les professeurs : la danse, l'escrime, l'équitation, le dessin, la musique figurent aussi au programme. Ces matières sont optionnelles et font l'objet d'un paiement séparé. Chaque élève dispose de sa propre chambre que les professeurs peuvent surveiller à travers une petite fenêtre.

Le premier lundi de chaque mois, se déroule un examen public auquel les parents sont invités à assister ainsi que, parfois, des membres de l'émigration française, comme le chevalier d'Augard, émigré français employé à la Bibliothèque publique impériale, et, plus tard, en 1806, lorsque l'institut sera dirigé par l'abbé Macquard, le comte Joseph de Maistre, célèbre écrivain et penseur catholique. Ce dernier fut très critique à l'égard de l'enseignement prodigué par les bons pères : il n'y voyait qu'exercice de la mémoire, enflure rhétorique et charlatanisme.

Le programme du lycée Richelieu d'Odessa, dont l'abbé Nicolle s'occupera après son départ de Saint-Pétersbourg, peut nous donner une idée des principes d'éducation et d'enseignement que l'abbé voulait mettre en pratique dans son établissement. L'effectif des élèves ne doit pas être trop important, afin de conserver à l'enseignement son caractère particulier, mais pas trop réduit non plus, pour maintenir une certaine émulation au sein des classes. Il est extrêmement important de conserver une « unité permanente des principes », dans l'esprit de Rousseau, aussi les élèves doivent-ils rester dans le même établissement pendant toute la durée de leurs études. Le pensionnat doit être divisé en deux niveaux, de huit à treize ans, et au-delà de treize ans, afin de mieux prendre en compte l'âge des

158. Il s'agit du n 115 , occupé actuellement par l'Institut des chemins de fer. M. I. Moroškin, Iezuity v Rossii v carstvovanie Ekateriny II i do našego vremeni [Les Jésuites en Russie sous le règne de Catherine II et jusqu'à notre époque], 2 vol., SPb., 1867-1870, t. 2, p. 113; Istorija pamjatnikov arhitektury i gradostroitel'stva Moskvy, Leningrada i ih prigorodov [Histoire des monuments d'architecture et d'urbanisme de Moscou, de Leningrad et de leurs environs], M., 6 t., 1985-1991, t. 2.

159. M.-J. Rouët de Journel, La Compagnie de Jésus en Russie..., op. cit., p. 52.

160. Frappaz, Vie de l'abbé Nicolle..., op. cit, p. 348. 
élèves ${ }^{161}$. Pour l'enseignement des langues étrangères, l'abbé préconisait la méthode suivante : la comparaison du texte en langue étrangère avec sa traduction, l'utilisation de la traduction mot à mot pour l'apprentissage accéléré de la syntaxe. Toutefois, il reconnaissait qu'une telle approche était insuffisante pour bien apprendre les langues vivantes.

Cet établissement se distingue, bien évidemment, de la majorité des écoles privées créées en Russie au XVIII ${ }^{\mathrm{e}}$ siècle. Les conditions de son ouverture sont tout à fait spécifiques : il s'agit d'une entreprise soutenue par les autorités (mais pas aussi directement que dans le cas de Carbonnet) et la clientèle de Nicolle est d'un niveau social plus élevé que celle qu'on pouvait voir habituellement dans les pensionnats. De plus, il s'agit en fait d'un établissement fermé, destiné uniquement à l'aristocratie. Enfin, le plus important, son personnel était presque entièrement constitué de religieux catholiques qui étaient en même temps des pédagogues professionnels, phénomène inconnu jusque-là en Russie.

Il est temps de tirer quelques conclusions. Les pensionnats étrangers fondés sur l'initiative privée ne font leur apparition en Russie qu'à partir des années 1740. On peut lier leur création à l'intérêt grandissant de la noblesse pour l'apprentissage des langues vivantes. Cet intérêt apparaît tardivement en comparaison d'autres pays européens, comme la Hollande, l'Angleterre ou la Prusse, où de tels établissements existaient déjà, en grande partie grâce aux huguenots.

Les pensionnats assuraient la scolarisation primaire et secondaire. Certains cherchaient à attirer une clientèle commerçante, d'autres une clientèle noble. Parmi ces derniers établissements quelques-uns préparaient leurs élèves à l'entrée dans les écoles militaires en proposant des disciplines comme l'artillerie, la physique ou le nivellement.

Le nombre de pensions va augmenter progressivement tout au long du siècle. Toutefois, la durée de vie de certains de ces pensionnats est relativement courte. Dans les deux capitales, les Français occupent des positions solides : un quart ou la moitié des directeurs de pension sont français. Ce chiffre est important, surtout si l'on tient compte de la taille de la communauté française, bien moins nombreuse que les communautés allemande et anglaise. On ne comptait d'ailleurs pratiquement pas d'Anglais dans ce secteur. Par ailleurs, il est à noter que les Russes sont très peu représentés ; il est vrai que la tradition voulait que les langues étrangères fussent enseignées par des natifs alors qu'à la même époque, dans les pensionnats suédois, le personnel local était majoritaire.

Un des premiers pensionnats étrangers dont nous ayons connaissance était de caractère familial ; le nombre de matières enseignées était très modeste et les langues y occupaient une place centrale. Avec le temps, les pensionnats s'agrandis-

161. Des extraits de ce plan, imprimés dans une brochure à part, sont cités dans l'ouvrage de l'abbé Frappaz, Vie de l'abbé Nicolle..., op. cit., p. 287 sq. 
sent et font appel à des professeurs extérieurs. Le choix des matières proposées s'uniformise progressivement et comprend, outre les langues, des disciplines d'enseignement général. Les maîtres de pension commencent à passer des annonces dans la presse pour recruter des élèves. Le plus souvent, et jusqu'au début du XIX ${ }^{\mathrm{e}}$ siècle, les pensionnats sont mixtes, malgré l'avis des religieux orthodoxes qui participaient parfois à l'inspection des établissements et se prononçaient pour une séparation nette des sexes.

Les pensionnats éducatifs en Russie sont semblables à ceux que l'on peut trouver en France, en Angleterre, en Hollande ou en Suède à la même époque. Le modèle en est en quelque sorte importé par ces maîtres de pension étrangers qui avaient déjà une expérience dans ce secteur. C'est grâce à eux qu'on trouve, à Moscou et Saint-Pétersbourg, les méthodes d'enseignement et la littérature pédagogique utilisées partout en Europe.

La qualité de l'enseignement dans les établissements français laisse souvent à désirer, notamment pour les disciplines générales. Ce n’est guère étonnant si l'on pense que les maîtres et les professeurs étaient rarement des enseignants de métier : on trouve parmi eux des militaires, des colons, des comédiens, etc. À Moscou cependant, un certain nombre de professeurs de l'université, dont des Français, dirigeaient des pensionnats dont la qualité était sans doute supérieure à la moyenne.

Ressentant le besoin d'établir un contrôle sur la qualité de l'enseignement et souhaitant aussi harmoniser l'enseignement primaire et secondaire, les autorités russes prirent une série de mesures : examen obligatoire des maîtres de pension et des professeurs, inspection des pensionnats, harmonisation des enseignements entre écoles publiques et privées, durcissement des conditions d'ouverture de pensionnats, etc.

Ces réformes incessantes furent souvent compromises par le manque de coordination entre les instances chargées de leur mise en œuvre (l'Académie des sciences, l'université de Moscou, la Commission pour la création d'écoles publiques, la Direction des écoles allemandes, etc.), ainsi que par le manque de suivi de leurs actions. On promulguait des oukases, mais on ne contrôlait pas vraiment leur application.

Cependant, les insuffisances de ces pensionnats ne doivent pas masquer leurs qualités. Ces écoles ont joué un rôle important dans la culture de certaines couches de la population urbaine en Russie. À cette époque, le système d'enseignement secondaire était encore rudimentaire, les pensionnats venaient donc compenser un manque d'enseignants et d'écoles. De plus, le rapport entre le nombre d'élèves et le nombre de professeurs est indiscutablement en faveur des écoles privées. Ces établissements furent un lieu d'échange entre la petite noblesse et la bourgeoisie russe et des étrangers venant d'Europe occidentale. Les gouverneurs étrangers et les maîtres de pension apportaient certains éléments de la civilisation de cette Europe : des connaissances, plus ou moins profondes, des livres, des cartes, des instruments de musique, des méthodes d'apprentissage des langues. Il ne faut pas oublier que ces écoles permettaient à des nobles et à des fonctionnaires peu fortunés d'accéder à l'éducation et elles leur offraient la possibilité d'apprendre rapidement des langues étrangères. 
L'un des derniers pensionnats ouverts en Russie au XVIII ${ }^{\mathrm{e}}$ siècle devint aussi l'établissement le plus connu dans son genre. Son fondateur, l'abbé Nicolle, et la plupart de ses enseignants étaient religieux. Mais le plus important est que, pour la première fois, ses professeurs étaient des pédagogues professionnels dotés d'une culture considérable. Les études dans ce pensionnat apportèrent à quelques nobles russes, outre la maîtrise parfaite du français, un intérêt pour la culture occidentale et une sensibilité aux idéaux humanistes des Lumières ${ }^{162}$.

rjeoutski@free.fr

(traduit du russe par Kumar Guha)

\section{Abréviations utilisées}

\section{Archives}

ANF Archives nationales de France (Paris)

CIAM Central'nyj istoričeskij arhiv Moskvy (Moscou)

[Archives historiques centrales de Moscou]

MAE Archives du ministère des Affaires étrangères de France (Paris)

RGADA Rossijskij gosudarstvennyj arhiv drevnih aktov (Moscou)

[Archives d'État des actes anciens de Russie]

RGIA Rossijskij gosudarstvennyj istoričeskij arhiv (Saint-Pétersbourg)

[Archives historiques d'État de Russie]

RNB Rossijskaja nacional'naja biblioteka (Saint-Pétersbourg)

[Bibliothèque nationale de Russie]

SPFA RAN Sankt-Peterburgskij filial Arhiva Rossijskoj Akademii nauk (SaintPétersbourg)

[Filiale de Saint-Pétersbourg des Archives de l'Académie des sciences de Russie]

\section{Presse et dictionnaires biographiques}

ČOIDR Čtenija v obščestve istorii i drevnostej rossijskih

[Conférences de la Société d'histoire et d'antiquités de Russie, revue]

MV Moskovskie vedomosti [La gazette de Moscou, journal] 
RBS Russkij biografičeskij slovar' [Dictionnaire biographique russe] pod red. A. A. Polovceva, SPb., 1896-1918, 25 vol.

$\mathrm{SPbV}$ Sankt-Peterburgskie vedomosti [La gazette de Saint-Pétersbourg, journal]

ŽMNP Žurnal Ministerstva narodnogo prosveščenija [Revue du ministère de l'Instruction publique] 


\section{ANNEXES \\ 1. Demande du maître de pension François-Eloi Saucerotte de se faire examiner à l'Académie des sciences de Saint-Pétersbourg}

« François Saucerotte Lorrain de la Nation a l'honneur de vous représenter que pour satisfaire de sa part à l'ordonnance qu'il a plu à Sa Majesté L'Impératrice de toutes les Russies de rendre aux fins de faire subir un examen à tous les Etrangers qui se trouvent dans ce vaste Empire et qui se donnent pour gens capables d'enseigner différentes langues, les sciences, les mœurs, et donner une éducation noble et instructive aux Elèves confiés à leurs soins, ledit Saucerotte se trouve en état d'enseigner méthodiquement la langue latine, les principes fondamentaux de la langue françoise, sa vraie prononciation, son goût, son génie, sa pureté et sa délicatesse, de même que le stile épistolaire françois qui supose la perfection de cette langue tant du côté de la connaissance de ses principes que de l'exercice et de l'habitude et qui convient particulièrement aux Secrétaires employés soit auprès de ses Ambassadeurs, ou Envoyés dans les Cours étrangères, soit auprès de ses Ministres particuliers. Le remontrant qui a acquis un grand usage du beau monde ose aussi se flatter d'être en état de donner une noble éducation aux jeunes cavaliers, en lui donnant de la part des Pères et Mères toute l'autorité qui lui est dû et nécessaire pour former l'esprit et le cœur de son Élève et le contenir dans les voies que la raison et la justice lui prescrivent. Saucerotte. »

Source : SPFA RAN, f. 3, op. 9, d. 78 (1757), f 3.

\section{Attestation délivrée par l'Académie des sciences à Louis Pontet, gouverneur et professeur au Corps des cadets nobles de l'armée de terre}

« 1757 году июня 4 дня дан сей аттестат находящемуся в доме у Гдна бригадира и лейб компании сержанта Матвея Звенского французского языка учителю Луи Понте, в том, что по печатному Его Императорского Величества указу сего же майа от 5 дня явился он при академии наук к экзамену, объявляя о себе, что он родился в Берлине от французского отца и матери и знает также по немецки, и с женою своею французской же нации обучает не токмо детей вышепоказанного господина Звенского, но и другие обоего полу (и принимает к себе в пензион - barré, V.R.) а по экзамену явилось, что (хотя он совершенным учителем называться не может - barré, V.R.), ежели кто доволен одной практикой французского языка, как то дети малолетние учатся оной более, нежели по регулам, то реченной Понте к такому делу употреблен быть может. Сей атестат за руками Гд Экзаменаторов академии наук профессоров и за академической печатью. »

Source : SPFA RAN, f. 3, op. 9, d. 78 (1757), f 9. 


\section{Avis de Jean-Baptiste Jude Charpentier, grammairien, professeur au gymnase de l'Académie des sciences, sur les connaissances du maître de pension de Challes}

« Je soussigné, Maitre de langue de la classe française du Gimnase de l'Académie des sciences certifie que le sieur de Challes parle et écrit passablement la langue française et qu'il en connait les principes en foi de quoi j'ai signé le présent certificat à StPétersbourg ce 20 may 1770. Charpentier. »

Source : SPFA RAN,f. 3, op. 9, d. 178 (1770 g.), f 3.

\section{Annonce de l'ouverture du pensionnat du Français Abraham Wille, magistr de l'université de Moscou}

«Магистр Художеств Императорского Московского Университета Абрам Виль и жена его Варвара Иванова дочь, прежде бывшая вдова Парат, извещают через сие, что они намерены принимать в содержимой ими благородный Пансион до 25 учениц, в котором обучаются они: Французскому и Русскому языкам по Грамматическим правилам, чистоту письма на обоих, Божию закону, Истории, Географии, Арифметике, рисованию, танцованию и играть на клавикордах; в праздные часы занимаются рукоделием, благородным девицам приличествующим - Означенная Виль сама неусыпно наблюдает за всеми их действиям, и ничего не щадит для образования их сердца и украшения разными полезными и приятными знаниями их разума Родители, которые удостоят их поручением детей своих на попечение, уверятся опытом в сей истине. Пансион же сей содержат они в собственном их доме, а прежде бывшем Генерала Кара, на Покровке, возле новой церкви Космы и Дамиана под № 110. »

Source: Moskovskie vedomosti, 27 oct.-3 nov. 1792.

\section{Annonce de l'ouverture du pensionnat d'Antoine Gaillard (?)}

«Прежде бывший учитель Антон Гальяр учреждает по дозволению Московскаго Приказа общественного Призрения Пансион для Благородных детей мужескаго полу, в котором как он, так и другие одобренные учители обучать будут методически следующим знаниям: Французскому, Российскому и Немецкому языкам, Закону Божию, Географии, Истории, Мивологии, Арифметике с прочими частями Математики и танцованию; желая соблюсти всю непорочность нравов детей ему вверенных, принимает он только таких, которым не менее 3 лет и не более 10. Пища здоровая, изобильная, свойственная возрасту и телосложению детей, всевозможная чистота, благоустройство и учтивость всегда обретутся в том доме, где число учеников простираться будет 
только до 12. Цена соразмерная будет возрасту, содержанию и наукам, каковых родители востребуют; а жительство он имеет на Никитской, в приходе Федора Студита в доме Николая Федоровича Жаркова. »

Source : Moskovskie vedomosti, 27 oct.-3 nov. 1792.

\section{Liste des pensionnats éducatifs de Moscou (1785-1800) ${ }^{163}$}

\begin{tabular}{|c|c|c|c|c|c|c|c|c|c|c|c|c|}
\hline \multirow[b]{2}{*}{ directeur du pensionnat } & \multirow{2}{*}{$\begin{array}{c}\text { fondé } \\
\text { en }\end{array}$} & \multicolumn{11}{|c|}{ existe en... } \\
\hline & & $\stackrel{\infty}{=}$ & হ & פ̄ & ฐ & হ & হั & $\stackrel{2}{2}$ & ลิ & $\stackrel{\infty}{2}$ & হ & ஜ \\
\hline Ауноской & $?$ & - & + & - & - & - & - & - & - & - & - & - \\
\hline Бартоли & 1772 & + & + & + & + & + & + & + & + & + & + & + \\
\hline Блеймер* / Blemeur, Иван & 1789 & - & + & + & + & + & + & + & + & + & + & + \\
\hline Борденау* / Bordenau & $?$ & + & + & + & + & + & + & + & - & - & - & - \\
\hline Бракель мадам & 1790 & - & + & + & - & - & - & - & - & - & - & - \\
\hline $\begin{array}{l}\text { Шампаньоло } \\
\text { (Шампаньолот)* / } \\
\text { Champagnolot }\end{array}$ & $1768 ?$ & - & - & - & - & - & - & - & - & - & - & - \\
\hline $\begin{array}{l}\text { Дефорсевиль* / de } \\
\text { Forceville, Луи Ноэль }\end{array}$ & 1794 & - & - & - & - & - & + & + & + & + & + & + \\
\hline Дефорж*/de Forges & $?$ & + & - & - & - & - & - & - & - & - & - & - \\
\hline $\begin{array}{l}\text { Дельсаль* / Delesalle, } \\
\text { Габриэль }\end{array}$ & 1794 & - & - & - & - & - & + & + & + & + & + & + \\
\hline $\begin{array}{l}\text { Дю Боф* / Du Bof ou } \\
\text { De Bof }\end{array}$ & $?$ & + & - & - & - & - & - & - & - & - & - & - \\
\hline $\begin{array}{l}\text { Эйзен (Эинсен)* / } \\
\text { Eisen von, Франц фон }\end{array}$ & $?$ & + & + & + & + & + & + & + & + & + & + & - \\
\hline Экстерн мадам & $?$ & + & + & - & - & - & - & - & - & - & - & - \\
\hline $\begin{array}{l}\text { Эмонора* мадам } \\
\text { (cf. Гимон-Демора) }\end{array}$ & 1791 & - & - & + & - & - & - & - & - & - & - & - \\
\hline Фрейсдорф & 1792 & - & - & - & + & - & - & - & - & - & - & - \\
\hline Гальяр*, Антон & 1792 & - & - & - & + & - & - & - & - & - & - & - \\
\hline Ганике*, Франсуа & 1792 & - & - & - & + & + & + & + & + & + & + & + \\
\hline Герильвальд & 1790 & - & + & + & + & + & - & - & - & - & - & - \\
\hline Гезиессен*, Иван & 1797 & - & - & - & - & - & - & - & + & + & + & + \\
\hline Гитте* & 1792 & - & - & - & - & - & - & - & - & - & - & - \\
\hline $\begin{array}{l}\text { Годен* мадам, passa à де } \\
\text { Леру* / de Leroux, } \\
\text { Мишель }\end{array}$ & 1790 & - & + & + & + & + & + & + & + & + & + & - \\
\hline Грейтлингер, Христиан & 1798 & - & - & - & - & - & - & - & - & - & + & - \\
\hline Горн ${ }^{*}$ & $?$ & + & - & - & - & - & - & - & - & - & - & - \\
\hline
\end{tabular}

163. Les annexes 6 et 7 sont établies à partir des documents disponibles et ne prétendent évidemment pas à l'exhaustivité. 


\begin{tabular}{|c|c|c|c|c|c|c|c|c|c|c|c|c|}
\hline \multirow[b]{2}{*}{ directeur du pensionnat } & \multirow[b]{2}{*}{$\begin{array}{c}\text { fondé } \\
\text { en }\end{array}$} & \multicolumn{11}{|c|}{ existe en... } \\
\hline & & $\stackrel{\infty}{=}$ & $\stackrel{8}{1}$ & פ & $\stackrel{2}{\beth}$ & $\stackrel{\Re}{\Xi}$ & $\stackrel{2}{I}$ & $\stackrel{2}{\Xi}$ & פ & $\stackrel{2}{\check{I}}$ & \& & $\underset{\infty}{\mathbb{\infty}}$ \\
\hline $\begin{array}{l}\text { Генш (cf. Енш, Генш } \\
\text { Saint-Pétersbourg) }\end{array}$ & $1773 ?$ & - & - & - & - & - & - & - & - & - & - & - \\
\hline $\begin{array}{l}\text { Гимон-Демора* мадам } \\
\text { (cf. Эмонора) }\end{array}$ & $1770 ?$ & - & - & - & - & - & - & - & - & - & - & - \\
\hline Жоли* / Joly ou Joli & 1792 & - & - & - & + & - & - & - & - & - & - & - \\
\hline Крафт, Дария & 1800 & - & - & - & - & - & - & - & - & - & - & + \\
\hline Кригер & 1793 & - & - & - & - & + & + & - & - & - & - & - \\
\hline $\begin{array}{l}\text { Кроненберг, ректор } \\
\text { лютеранской церкви }\end{array}$ & $?$ & + & + & + & + & + & + & + & + & + & + & + \\
\hline Лангер & $?$ & + & + & - & - & - & - & - & - & - & - & - \\
\hline Лебле* мадам & 1795 & - & - & - & - & - & - & + & + & + & + & + \\
\hline $\begin{array}{l}\text { Литвас, ректор } \\
\text { лютеранской церкви }\end{array}$ & $?$ & + & + & + & + & + & + & + & + & + & + & + \\
\hline $\begin{array}{l}\text { Мартен* / Martin, } \\
\text { Самюэль }\end{array}$ & $1770 ?$ & - & - & - & - & - & - & - & - & - & - & - \\
\hline Меард* / Méart & 1792 & - & - & - & + & + & - & - & - & - & - & - \\
\hline $\begin{array}{l}\text { Морибель* / Moribel, } \\
\text { Никола }\end{array}$ & 1792 & - & - & - & + & + & + & + & - & - & - & - \\
\hline Парат* / Parat & $1770 ?$ & - & - & - & - & - & - & - & - & - & - & - \\
\hline Презер, Анна & 1797 & - & - & - & - & - & - & - & + & + & + & + \\
\hline Пует* & 1791 & - & - & + & + & + & - & - & - & - & - & - \\
\hline Ромасков & 1790 & - & + & - & - & - & - & - & - & - & - & - \\
\hline Сен-Лебен*, Антон & 1795 & - & - & - & - & - & - & + & + & + & - & - \\
\hline $\begin{array}{l}\text { Сен-Никола* / Saint- } \\
\text { Nicolas, Жан-Годфруа }\end{array}$ & $\begin{array}{c}\text { fin } \\
\text { années } \\
1760\end{array}$ & - & - & - & - & - & - & - & - & - & - & - \\
\hline Стейнгер & 1794 & - & - & - & - & - & - & + & + & + & + & + \\
\hline Вандеренде & 1792 & - & - & - & + & - & - & - & - & - & - & - \\
\hline Виль*/Wille, Огюст Луи & 1786 & - & + & + & + & + & + & + & - & - & - & - \\
\hline Войтеховский, Ефим & 1779 & + & + & + & + & + & + & - & - & - & - & - \\
\hline Зеемильер* де & 1766 & - & - & - & - & - & - & - & - & - & - & - \\
\hline Зорг, Георг & 1794 & - & - & - & - & - & + & + & + & + & + & + \\
\hline
\end{tabular}

Légende

+ le pensionnat existe l'année indiquée, selon les rapports ;

- le pensionnat n'existe pas ;

* le maître de pension est probablement ou certainement d'origine française.

Les noms sont classés alphabétiquement ; la graphie en caractères latins est indiquée quand elle est connue.

Sources: K.V. Sivkov, «Častnye pansiony i školy Moskvy v 80-h gg. XVIII veka», Istoričeskij vestnik, nº 6, 1951, p. 315-323; et RGIA,f. 730, op. 1, d. 41. 


\section{Liste des pensionnats éducatifs de Saint-Pétersbourg}

\begin{tabular}{|c|c|c|}
\hline directeur du pensionnat & origine & $\begin{array}{l}\text { pensionnat } \\
\text { existe en... }\end{array}$ \\
\hline $\begin{array}{l}\text { Делагеин* / Delagein, Пьер Франсуа } \\
\text { Реми }\end{array}$ & France & $1757 *$ \\
\hline Реймарус, Иоган Христиан & & $1757 *$ \\
\hline Сосерот*/Saucerotte, Франц & France & 1757 \\
\hline Кювилье*/ Cuvillier, Жан & Paris & 1757 \\
\hline Жамбеле, Гвиллон (Гийом?) & Suisse & 1757 \\
\hline Биес* / Bies, Жозеф & Bourgogne & 1757 \\
\hline Бранк*, Жан & Strasbourg & 1757 \\
\hline Купер / Couper, Карл Густав & $\begin{array}{l}\text { Vyborg, } \\
\text { « de nation allemande » }\end{array}$ & 1757 \\
\hline Спарк*, Мишель, гугенот & France? & 1757 \\
\hline Валтьер* / Waltier, Петр с женою & France & 1757 \\
\hline Геплин, Иоган & Finlande & avant 1757 \\
\hline $\begin{array}{l}\text { Преториус / Praetorius, Фридрих, } \\
\text { пастор }\end{array}$ & Livonie & 1757 \\
\hline Делаваль* / De Laval, Петр & France & 1757 \\
\hline Салов*/Salow, Андрей & Colmar, Alsace & 1757 \\
\hline Доровиус / Dorovius, Юзан Вилгельм & Riga & 1757 \\
\hline Грозман, Иоган & Saint-Pétersbourg & 1757 \\
\hline Штиллау & & 1765 \\
\hline $\begin{array}{l}\text { Шаль* де / Challes de, Жан Теофиль с } \\
\text { женою }\end{array}$ & France & $1770-1772$ \\
\hline Эргард, Христофор И. & & $1771 *-(1784-1788)$ \\
\hline $\begin{array}{l}\text { Модрю дю Бокаж* / Maudru du } \\
\text { Bocage, Жан-Батист }\end{array}$ & & 1775 \\
\hline $\begin{array}{l}\text { Жоли-Дебромт* / Joly-Debromt, } \\
\text { Жозеф }\end{array}$ & France & $1775-$ \\
\hline Жирар* мадам & France & 1776 \\
\hline Дельсаль* / Delesalle, Филипп-Огюст & France & 1779 \\
\hline Ранекен, Федор & $\begin{array}{l}\text { «originaire } \\
\text { d'Allemagne » }\end{array}$ & $(1784-1788)$ \\
\hline Баман, Николай & Hambourg & $1787-1794-$ \\
\hline Ганцелман & & $(1784-1788)$ \\
\hline Оллери* / Aullery, Жорж Луи & France & $(1784-1788)$ \\
\hline Франц, Крестьян & Hambourg & $(1784-1788)$ \\
\hline Колбе, лютеранский пастор & & $(1784-1788)$ \\
\hline
\end{tabular}




\begin{tabular}{|c|c|c|}
\hline directeur du pensionnat & origine & $\begin{array}{l}\text { pensionnat } \\
\text { existe en... }\end{array}$ \\
\hline Веяман, Иоган & & $(1784-1788)$ \\
\hline Шумахер, Людвиг & Saint-Pétersbourg & $(1784-1788)$ \\
\hline Вендемейер, Иван & & 1786-1794- \\
\hline Пицкер / Pitzki, Иоган Фридрих & & $(1784-1788)$ \\
\hline Бардевик, Мария & & 1786-1794- \\
\hline Ришар*/ Richard, Николай, затем Мари & France & $1786-1800-$ \\
\hline Бетерлинг, Федор & «Allemand libre» & $(1784-1788)$ \\
\hline Рениболт, Фридрих, пастор & & $(1784-1788)$ \\
\hline Перезинотова, Анна & & avant 1784 \\
\hline Тургенев, Василий & «bourgeois local» & $(1784-1788)-1794-$ \\
\hline $\begin{array}{l}\text { Жилет* / Gillet, Иван, профессор } \\
\text { Академии Художеств }\end{array}$ & France & $(1784-1788)$ \\
\hline Катенкампф, Иоган & Hanovre & $(1784-1788)$ \\
\hline Фрицлер, Эрнст & Türingen & $1786-1799$ \\
\hline Масон*/Masson, Иван & Strasbourg & $(1784-1788)$ \\
\hline $\begin{array}{l}\text { Девильнев* / Villeneuve ou Villeneuff } \\
\text { de, Якоб }\end{array}$ & France & $(1784-1788)$ \\
\hline Жоффруа* вдова, Мария & France & $(1784-1788)$ \\
\hline Мортье* девица & France? & $(1784-1788)$ \\
\hline Ленк*/Linque & France & $(1784-1788)$ \\
\hline Юрансон / Juranson & & $(1784-1788)$ \\
\hline Шихтер / Chichter & & $(1784-1788)$ \\
\hline Палмье* / Palmier & France? & $(1784-1788)$ \\
\hline Какс или Кок / Cacks & Angleterre & $(1784-1788)$ \\
\hline Книрим, Иоган Герман & & $(1784-1788)$ \\
\hline Давизон, Андрей & & fin 1760-début 1780 \\
\hline Вальтер, Генрих Вильгельм & & $1784-1788$ \\
\hline Цизмер, Елизавета & & 1786-1800- \\
\hline Билтерлинг, Фердинанд Иоган & & $1784-1788$ \\
\hline Френц, Христиан & & $1784-1788$ \\
\hline Краббе, Катерина & & 1786-1800- \\
\hline Эклебен, Мария & & $1788-1799$ \\
\hline Рокерговер, Вильгельм & & $1793-$ \\
\hline Франк, Катерина & & 1791 \\
\hline Генш, Вениамин & & 1792 \\
\hline Роланд* / Roland, Георг & France? & $1792-$ \\
\hline
\end{tabular}




\begin{tabular}{|l|l|l|}
\hline \multicolumn{1}{|c|}{ directeur du pensionnat } & \multicolumn{1}{c|}{ origine } & \multicolumn{1}{c|}{$\begin{array}{c}\text { pensionnat } \\
\text { existe en... }\end{array}$} \\
\hline Франкен, Федор & & $1793-$ \\
\hline Вицман, Август & & 1792 \\
\hline Стремер, Мария & & $1793-1800-$ \\
\hline Аменде, Эмануэль & & $1794-1800-$ \\
\hline Антовер, Анна & & 1789 \\
\hline Кампер, Мария & & $1793-$ \\
\hline Девенисов, Николай & & $1794-$ \\
\hline Медовщиков, Андрей & & 1794 \\
\hline Глумер, Сусанна & & $1799-1800-$ \\
\hline Гелизин & & $1799-$ \\
\hline Штелцер, Иван & & $1799-1800-$ \\
\hline Енш, Иван (сf. Генш, Мозсои) & & $1799-1800-$ \\
\hline Жирарден*/ Girardin, Давыд & France & $1799-1800-$ \\
\hline Хелм, Каролина & & $1799-1800-$ \\
\hline Минепот, Анна & & $1799-1800-$ \\
\hline Криль, Иван & & $1799-1800-$ \\
\hline Гальвиль*, София & France ? & 1799 \\
\hline Квартано, Осип & & 1799 \\
\hline Мейер, Ефим & & 1799 \\
\hline Жакино*, Осип & $1799-$ \\
\hline Шпис, Наталия & 1799 \\
\hline Франкен, Федор & & $1799-1800-$ \\
\hline Вириде, Петр & & $1800-$ \\
\hline Дюмер*, Анна & $1800-$ \\
\hline Мейеринг, Карл & $1800-$ \\
\hline Николь* / Nicolle, аббат Шарль & $1794-1800-$ \\
\hline Доминик & & \\
\hline Лейтлов, Иван & & \\
\hline
\end{tabular}

\section{Légende}

Делагеин* l'astérisque après le nom de famille signifie qu'il s'agit d'un Français ;

1757 première mention du pensionnat ;

1757* l'astérisque après la date signifie que le pensionnat a été créé cette année-là ;

1775- le tiret signifie que le pensionnat a probablement continué d'exister après la date indiquée ;

1770-1772 dates limites de l'existence du pensionnat;

(1784-1788) les dates entre parenthèses correspondent aux dates limites du dossier d'archives.

Les noms sont classés dans l'ordre chronologique.

Sources : RGIA, f. 730, op. 1, d. 41, 70 ; SPFA RAN, f. 3, op. 9, d. 78, 80, 85, 92, 170, 178, 189, 225, $239,262,289,329,353,355,373,377,704$. 


\section{Quelques livres édités en Russie et utilisés dans l'enseignement du français au XVIIII siècle ${ }^{164}$}

Astahov, Ivan / Астахов, Иван, Самый легчайший способ ко обучению франиускому языку то есть: говорить, читать и писать; или Новая франиуская грамматика, обучающая легко, ясно и основательно, самоучкою учитися хотящих франиускому языку, SPb., 1782, [4]-91 р., in- $8^{\circ}$ (2e partie, sous le même titre : $1787,[3]-49$ p., in- $8^{\circ}$ ).

Boujot, Louis / Бужо, Луи, Краткие правила франиузской грамматики. Сочиненныя в пользу учащагося в Сухопутном шляхетном кадетском корпусе юношества, SPb.: Тип. Сухопутного шляхетного кадетского корпуса, 1761, in- $8^{\circ}, 221$ p. $\left(1400\right.$ ex. $\left.{ }^{165}\right)$

Boulay (?) / Буле, Франиузская грамматика на франиузском языке, т. 1, $\mathrm{SPb} .:$ Тип. Сухопутного шляхетного кадетского корпуса, 1763 (2 200 ex.).

Bunin, Vasilij / Бунин, Василий, Франиусская грамматика: С кратким употреблением на все части / Сочиненная в Сухопутном шляхетном кадетском корпусе подмастерьем Васильем Буниным, SPb., 1758, [6]158 p., in- $8^{\circ}$.

Des Pepliers, Jean-Robert, SoKol'skis, Fëdor / Пеплие, Жан-Робер, Сокольский, Федор, Франиузская грамматика: При которой исправленный словарь, дружеские разговоры, пословицы, достойные примечания истории и пристойные на разные случаи писма. Изданная на немецком языке Г. Пеплиером, а на российской переведенная д.с.к. Федором Сокольским, М.: Унив. тип., у Н. Новикова, 1780, [2]-489 р. (2e d.: M., 1788).

Des PePliers, Jean-Robert, TePlov, Vasilij / Пеплие, Жан-Робер, Теплов, Василий, Собрание слов франиузских, российских и немецких. Из «Nouvelle et parfaite grammaire royale française et allemande Пеплие. Переведено В.E. Тепловым, SPb.: Тип. Акад. наук, 1780, 149 p. (tirage 4000 ex.; autres éd.: 1772, 1776, 1000 ex.).

FABIAN, Ivan / фабиан, Иван, ABC instructif, pour apprendre aux enfants les éléments de la langue françoise = Поучительная азбука, преподающая детям начальныя правила франиузскаго языка, М.: Унив. тип., у Ридигера и Клаудия, 1799, 74 p., in- $8^{\circ}$.

164. Cette liste est constituée dans le cadre d'une enquête sur la littérature scolaire utilisée en Russie, que nous menons avec Wladimir Berelowitch et qui n’en est qu'à ses débuts.

165. Le tirage de certaines de ces éditions est indiqué d'après les informations contenues dans : S. P. Luppov, « Tipografija Suhoputnogo ·Šljahetnogo Kadetskogo Korpusa v 1757-1763 gg. ee zakaznye izdanija » [La Typographie du Corps des cadets nobles de l'armée de terre en 1757-1763 et ses publications de commande], Kniga i biblioteki v Rossii v XIV - pervoj polovine $X I X v$. [Le livre et les bibliothèques en Russie au XIV -début du XIX ${ }^{\mathrm{e}}$ s.], Leningrad, 1982, p. 5-25, et dans le catalogue de la Bibliothèque nationale de Russie. 
FABIAN, Ivan / фабиан, Иван, Nouveaux dialogues français et russes divisés en 99 thèmes sur les neufs parties du discours, ou Manière très facile pour apprendre les principes de la grammaire française par Jean Frédéric Fabian = Новые франиузские разговоры с российским переводом, разделенные на 99 задачь, показывающих свойство каждой части речи, или Легчайший способ узнать правила франиузской грамматики, Изданный Иваном Фабианом, М.: Губ. тип., у А. Решетникова, 1799, III-132 p., in-8 (texte bilingue).

Francuzskaja azbuka, Французская азбука, SPb., 1762 (600 ех.).

GAUtier, J. R. / Готье, Ж. Р., Легкой способ научиться франиузскому языку: Основанной на примерах лучших авторов и расположенной на четьре части. Ж. Р. Готье, 4 части, $\mathrm{SPb} .:$ При Мор. шляхет. кадет. корпусе, 1777-1779, in- $8^{\circ}$ (bilingue, 2e éd. : SPb., 1787, 800 ex.).

GoRmič, Philippe / Гормич, Филипп, Практическая франиузская грамматика, Изданная для средних франиузских классов Благороднаго университетскаго пансиона, учителем означеннаго пансиона Филиппом Гормичем, М.: Унив. тип., у Ридигера и Клаудия, 1800, 194 р., in- $8^{\circ}$ (2e éd.: M., 1809).

GorLICKIJ, Ivan / Горлицкий, Иван, Grammaire française et russe en langue moderne accompagnée d'un petit dictionnaire pour la facilité du commerce d'Ivan Gorlitski = Грамматика франиузская и руская нынешняго языка: Сообщена с малым лексиконом ради удобности сообщества, SPb.: [Typ. de l'Académie des sciences], 1730, 64 p., in- $8^{\circ}$.

KaržAvin, Fëdor / Каржавин, Федор, Le guide par Théodore Karjavine = Вожак, показывающий путь к лучшему выговору букв и речений франиузских. Новая и полная фрраниуская азбука: по которой можно самому выучиться, по правилам или без правил, акибы с помощию некоего путеводителя или Вожака, выговаривать чисто и писать порядочно слова не только нынешняго но и древняго франиускаго языка. Собранная трудами публичнаго разных языков учителя и переводчика Феодора Каржавина, SРb.: Печ. у И. К. Шнора, 1794, 288 р.

LAVAL de / Лавал де, Explication de la grammaire françoise avec des observations, et des exemples sensibles sur l'usage de toutes les parties = Изъяснение новой франиусской грамматики: С примечаниями и примерами на все части слова, SPb.: печатана в Санкт-Петербурге при Императорской Академии наук, 1752, [22]-687-[10] p. (texte bilingue).

Protopopov, Vasilij / Протопопов, Василий, Новый легчайший способ $к$ познанию начал франиузскаго языка,: Содержащий в себе полное и основательное наставление в произношении, взятое из лучших грамматик писанных на одном франиузском языке и удобнейшее к изучению самоучащихся чистому и правильному произношению, сокращенный словарь заключающий в себе самыя употребительныя слова и речи, краткия $и$ нужныя разговоры, сверх сего обязательнейшие и учтивые комплименты франиузскаго языка, / 
Изданный Васильем Протопоповым, SPb.: Печатано на иждивении Г. П.: Имп. тип., 1789 , in-8 ${ }^{\circ}$ (autre éd.: 1790).

RANZOw, Lüdwig von / Ранцов, Людвиг фон, Грамматика Франиузская, с русским переводом, основанная на лучших авторах, сочинена для употребления российского юношества Лудовиком графом Раниовым, М.: Печ. при Имп. Моск. ун-те, 1769, [8]-272-[6] р., in-8 .

Restaut, Pierre, TePlov, Vasilij / Ресто, Пьер, Теплов, Василий, Франиусская грамматика; Собранная из разных авторов г. Ресто; А на российской язык переведенная Васильем Тепловым, SPb., 1762, [2]-380-149 p., in-8 , 2400 ex. (1éd., 1752, 1225 ex.; 3e éd., 1777, 1000 ex. ; 4e éd., 1787, 1212 ex. ; 5éd., 1809).

SigisBeK, Краткая фрраниузская грамматика, сочиненная Г. Сигисбеком, $\mathrm{SPb} ., 1770^{166}, \mathrm{in}^{\circ} 8^{\circ}$.

Soc, Ivan / Соц, Иван, Новая фрраниузская грамматика: Содержащзая в себе краткия правила франиузскаго языка; Сочинена франиузскаго этимологическаго при гимназиях Имп. Московскаго университета класса учителем, Иваном Соцом, М., 1790, ч. 1, 160 р., ч. 2, 94-[2] p., in$8^{\circ}$.

SokolovsкiJ, Martyn / Соколовский, Мартын, Сокращенная фрранцузская грамматика, расположенная по вопросам и ответам, с российским переводом вновь исправлена с прибавлением сочинения частей слова Мартыном Соколовским = Grammaire française abrégée faite par demandes et réponses avec la traduction russe, М.: Печ. при Имп. Моск. унте, 1770 , in- $8^{\circ}$ (autres éd.: $1778,1781,1788,1794$ ).

Sokraščennaja s vokabulami, Сокращенная франиузская грамматика c вокабулами, $\mathrm{SPb} ., 1730^{167}$, in-8.

Weguelin, Jean Philippe / Вегелин, Жан Филипп, Новые разговоры франиузские и российские: Разделенные на 130 уроков для употребления юношеству и всем начинающим учиться сим языкам. Изданнье Иоанном Филиппом Вегелином. М.: Тип. Комп. Типографич., 1789, IX-348 p., in-12 (autres éd.: 1793, 1799 ; texte bilingue).

Weguelin, Jean Philippe / Вегелин, Жан Филипп, Новый методический способ учиться хорошо читать: Для употребления обучаюшимся франиузскому языку, с присовокуплением словаря на франиузском и российском языках. Изданный Иоанном Филиппом Вегелином, М.: Тип. Комп. типографич., 1791,118 р., in $8^{\circ}$.

Weguelin, Jean Philippe, Cvetкov, Mihail / Вегелин, Жан Филипп, Цветков, Михаил, Введение к обучению грамматики франиузской: В пользу

166. Selon V. S. Sopikov, Opyt rossijskoj bibliografii [Essai de bibliographie russe], SPb., 1904. Les livres dont les références sont tirées de Sopikov ne figurent pas dans le Svodnyj katalog russkoj knigi graždanskoj pečati XVIII veka, 1725-1800 [Catalogue collectif des livres du XVIII siècle en caractères russes modernes, 1725-1800], M., 1962-1976, vol. 1-5, suppl., il n'en existe donc probablement aucun exemplaire conservé.

167. Ibid. 
юношества. Перевел И. М. У. бакалавр Михайло Цветков, М.: Тип. при Театре, у Хр. Клаудия, 1793, [20]-224 p., in- $8^{\circ}$ (texte bilingue).

\section{Quelques livres populaires utilisés dans l'enseignement du français en Europe et connus en Russie}

BARTHÉlemy, Louis, Grammaire des dames, ou Nouveau traité d'orthographe françoise, Genève : P. Barde, 1785, VIII-240 p., in- $8^{\circ}$.

Demoustier, Charles-Albert, Lettres à Émilie sur la mythologie, par M. Demoustier, $1^{\mathrm{re}}\left[\mathrm{-4}^{\mathrm{e}}\right]$ partie, Paris : Desenne, $1792,3^{\mathrm{e}}$ éd., in- $8^{\circ}$.

Des PePliers, Jean Robert, Grammaire Royale françoise \& allemande : contenant une methode nouvelle \& facile pour apprendre en peu de temps la langue françoise = Königliche Frantzösch- und Teutsche Grammatic ; ecrite par Mr. Jean Robert des Pêpliers, Informateur de Monseig. le Duc de Bourgogne, Berlin : Vöcker, 1689 (Nombreuses rééditions au cours du XVIII siècle, généralement sous le titre : Nouvelle grammaire royale française et allemande).

Fénélon, François de SAlignac de La MotTe, Les Avantures de Télémaque, fils d'Ulysse..., 1762, in-12 ${ }^{\circ}$, t. 1-2 (Cet ouvrage connaît beaucoup de rééditions et devient le livre le plus lu dans les écoles au cours du siècle des Lumières, il est utilisé pour l'enseignement du français dans toute l'Europe. Il y a eu des livres écrits dans la vogue de Télémaque dont certains ont été traduits en russe, par ex. : K. F. Lambert / К. Ф. Ламбер, Новый Телемак..., Partie 1-3 $\mathrm{SPb} ., 1761-1762,1500 \mathrm{ex}$.).

GiRARD, Gabriel, abbé, La Justesse de la langue françoise, ou les Différentes significations des mots qui passent pour synonymes..., Paris : L. d'Houry, 1718, in-12 ${ }^{\circ}$, LVIII-263 p. (et ses rééditions sous le titre : Dictionnaire des synonymes).

LA Touche, Pierre de, L'Art de bien parler françois, qui comprend tout ce qui regarde la grammaire \& les façons de parler douteuses. Nouvelle édition, revue exactement sur la Grammaire de Mr. l'abbé Regnier Desmarais, sur le Dictionnaire de l'Academie françoise... Tome premier [-second], Amsterdam : chez R. \& G. Wetstein, 1710, 2 vol., in-12 ${ }^{\circ}$.

LePrince de Beaumont, Marie, Le Magasin des enfans, ou Dialogues d'une sage gouvernante avec ses élèves de la première distinction, dans lesquels on fait penser, parler, agir les jeunes gens suivant le génie, le tempérament et les inclinations d'un chacun... on y donne un abrégé de l'histoire sacrée, de la fable, de la géographie, etc., le tout rempli de réflexions utiles et de contes moraux... par Mme Leprince de Beaumont..., Lyon : J-B. Reguilliat, 1758, 4 parties en 2 vol. in- $12^{\circ}$ (Tout comme Les Avantures de Télémaque, réédité et traduit de nombreuses fois, le Magasin comptait parmi les livres les plus étudiés dans les écoles à cette époque. Le livre a été traduit et édité en Russie : Детское училище или нравоучительные разговоры, [перевел П. Свистунов], ч. 1-2, SPb., 1762, 2000 ех.). 
PRUNAY de, Grammaire des dames, où l'on trouvera des principes sûrs et faciles pour apprendre à ortographier correctement la langue française, avec les moyens de connaître les expressions provinciales, de les éviter et de prévenir chez les jeunes demoiselles l'habitude d'une prononciacion vicieuse, Paris : Lottin l'aîné, 1777, XXXVI-322 p., front., in-12².

Restaut, Pierre, Principes généraux et raisonnés de la grammaire française : par demandes et par réponses..., Paris : J. Desaint, 1730, XXVI-321 p. ; Idem, Principes généraux et raisonnés de la grammaire françoise avec des observations sur l'orthographe... et un abrégé des règles de la versification françoise..., Paris : Le Gras, Lottin, Desaint et Chaubert, 1732, XX-552 p., planche, in- $8^{\circ}$. Une édition abrégée : Abrégé des principes de la grammaire françoise..., Paris : Le Gras, Prault, Lottin et Desaint, 1739, IV-115 p., in$12^{\circ}$. Ou encore une édition à l'usage des collèges et des pensions : Abrégé de la langue françoise (ou grammaire françoise), contenant les principes généraux $d u$ discours, avec quelques règles de syntaxe \& d'orthographe pour servir de préparation à l'étude du Nouveau rudiment et de la Méthode latine. À l'usage des collèges et des pensions... Paris : chez Desaint \& Saillant, 1748. Cette grammaire fut imprimée et traduite plus d'une fois dans différents pays d'Europe, par exemple : Idem, Nouvelle et parfaite grammaire françoise = Neue und vollständige französische Grammatic... aus dem französischen des Herrn Restaut..., Mayence : F. Varrentrap, 1749, VI-594 p., in-16 ${ }^{\circ}$. Restaut a été également traduit en russe, voir par exemple la traduction effectuée par Vassilij Teplov et sortie en 1752 (rééditée en 1762, 1777, 1787, 1809, etc.). 